\title{
The Impressive Chemistry, Applications and Features of Ionic Liquids: Properties, Catalysis \& Catalysts and Trends
}

\author{
Brenno A. D. Neto ${ }^{*, a}$ and John Spencer ${ }^{b}$ \\ ${ }^{a}$ Laboratory of Medicinal and Technological Chemistry, Chemistry Institute, University of Brasília (UnB), \\ Campus Universitário Darcy Ribeiro, P.O. Box 4478, 70904-970 Brasília-DF, Brazil \\ ${ }^{b}$ Department of Chemistry, School of Life Sciences, University of Sussex, Falmer, Brighton, \\ East Sussex, BN1 9QJ, United Kingdon
}

\begin{abstract}
Algumas das nossas contribuições para o desenvolvimento da área da catálise em líquidos iônicos são descritas. Além disto, o uso de ligantes ionofílicos bem como a utilização de catalisadores com "etiquetas iônicas" são apresentados e discutidos. Devido à importância dos líquidos iônicos, as suas propriedades fisicoquímicas de interesse bem como a sua organização supramolecular são temas discutidos.
\end{abstract}

Some of our contributions to the development of catalysis in ionic liquids are described. Also, the use of ionophilic ligands and catalysts with ionic tags are presented and discussed. Due to the importance of ionic liquids, some physicochemical properties of interest and their supramolecular organization are described.

Keywords: ionic liquids, catalysis, ionic tags, mass spectrometry

\section{Introduction}

For many years, ionic liquids (ILs) were regarded as promising solvents and materials for a wealth of possible applications. Nowadays, however, ILs have superseded this status and have become an amazing reality. Indeed, ILs are currently used in a plethora of industrial processes, as reviewed elsewhere. ${ }^{1}$ Nowadays, there is no doubt about the great utility of ILs in both modern chemistry and technological applications. ${ }^{2}$ The importance of ILs can be easily evidenced by measuring the number of important reviews published on the subject and their related applications. Many literature surveys are available to different audiences spanning disciplines from asymmetric catalysis, homogeneous catalysis, organic synthesis, green chemistry, biotransformations, analytical chemistry, industrial applications, enzymatic reactions and others. ${ }^{3-12}$

Despite all advances on the basic properties, comprehension and use of ILs, there are still many things left to be achieved. And, somewhat surprising, their physical and chemical properties still have many issues under debate. The definition of ILs has been a subject

*e-mail: brenno.ipi@gmail.com of much debate over the years, especially in the last decade. and there are still some contrasting definitions. In the present manuscript the term "ionic liquid" will be used to describe supramolecular structures composed entirely of ions that melt below $100{ }^{\circ} \mathrm{C}$ or typically close to room temperature. Commonly, one can find an organic cation (e.g., ammonium, phosphonium, imidazolium, pyridinium and others) with an anion of relatively low coordination strength (e.g., hexafluorophosphate, halides, acetates, bis-trifluoromethanesulfonimide, tetrafluoroborate and others).

To understand the effect of a chosen IL on a specific reaction, it is necessary to have prior knowledge of their organizational behavior, physicochemical properties and reactivity. Only then it is possible to envisage a beneficial effect over organic and catalytic reactions using these materials. The reader can find many articles covering the subjects of properties, reactivity and organization in the literature, thus our option was for a brief description on the important issues of interest to our discussion rather than focus on their properties and organizational behavior. Results from other groups will be cited only if necessary for a better understanding of a specific property, result or for illustrative comparison. Considering that the scope of 
the present manuscript is rather limited, the reader is urged to peruse comprehensive reviews on the subject already cited herein. Moreover, this article will place an emphasis on imidazolium chemistry, which encompasses, no doubt, a rich, attractive, important, challenging and controversial class of ILs.

Imidazolium-based ILs occupy an important part, and much studied aspect of, IL chemistry. Their structural threedimensional organization reveals one major aspect of these salts: they display structural directionality mainly due to hydrogen bonds. ${ }^{13,14}$ The net result is a nano-organization of inclusion compounds through ionic-pairing where the IL itself acts as an entropic driver forming a supramolecular network (aggregate formation), i.e., the so called "ionic liquid effect". It is worth highlighting that the organization is spontaneous and of considerable extension, therefore, the effect is expected to be amplified due to the supramolecular aggregate formation rather than based only on the isolated cation or anion. Scheme 1 illustrates a basic organization of imidazolium-based ILs.

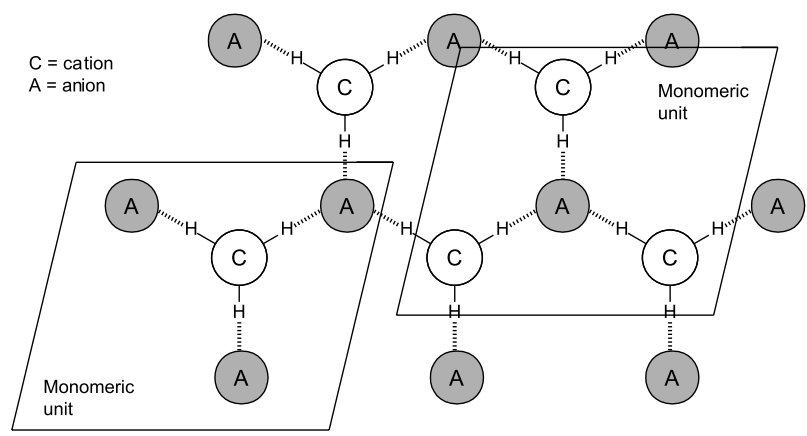

Scheme 1. Representative 2D basic arrange of imidazolium-based ionic liquids. Note that a monomeric unit of a cation is basically surrounded by three anions and the monomeric unit of an anion surrounded by three cations.

The tendency towards ion-pairing, aggregation and high organization is not restricted to pure ILs. Indeed, it was possible to observe in several cases that ILs showed a beneficial and direct effect on the reaction rate (and/ or selectivity) during a specific transformation. The capacity of these salts to promote reactions that are difficult to perform in classical organic solvents has already been described for many cases. ${ }^{15-17}$ These effects can be attributed to the inherent ionic nature and self-

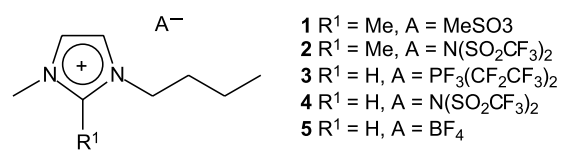

organization promoted by these salts that are capable of (co-)promoting the formation and stabilization of ionic or polar intermediates (or transition states) through different types of ion pairing and supramolecular aggregates formation, thus resulting in a spontaneous nano-organization of the system. In other words, these salts are acting as entropic drivers to the system, which is the ionic liquid effect in action.

In this account, our investigative effort to the development of organic and catalytic reactions in imidazolium-based ILs is described, the development and application of ionically-tagged catalysts, as our contribution to a better understanding of the organization, reactivity, properties and application of this intriguing class of materials.

\section{Distillation of Ionic Liquids and the Controversy of Carbenes}

For long one assumed that ILs were non-volatile. Nevertheless, this property was only an assumption that has dominated the chemistry of ILs since its origins than properly asserted with scientific accuracy. Since Earle's publication ${ }^{18}$ showing that some ILs are indeed distillable, many discussions have been found about this issue. The exactly mechanism of how an IL behaves during a distillation process varies according to its specific ionic composition and possibility of carbene formation. The possibility of carbene formation cannot be discarded, but it has not been proven without doubt. In this sense, the distillation process by means of atmospheric-pressure chemical ionization mass spectrometry experiments (APCI-MS and APCI-MS/MS) was investigated in our previous work. ${ }^{19}$ Six different imidazolium-based ILs (Figure 1) were "distilled" and the species involved in the process investigated.

Results indicated that all the ILs distilled as neutral aggregates of a general formula $[\operatorname{ImA}]_{n}$, where $\operatorname{Im}$ is the imidazolium cation, $\mathrm{A}$ is the anion and $\mathrm{n}$ varies from 1-3. The concentration of aggregates with $n=2$ or 3 increased upon increasing the temperature. These observations allowed a mechanism proposition for the process, as shown in Scheme 2.

It is important to highlight that, indeed, there is no consensus on the mechanism involved in the distillation

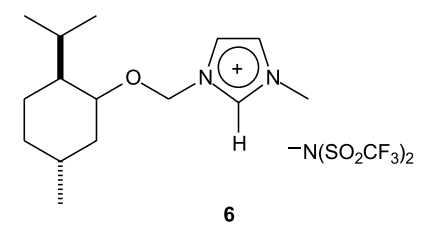

Figure 1. Imidazolium-based ionic liquids investigated (“distilled”) by APCI-MS. 


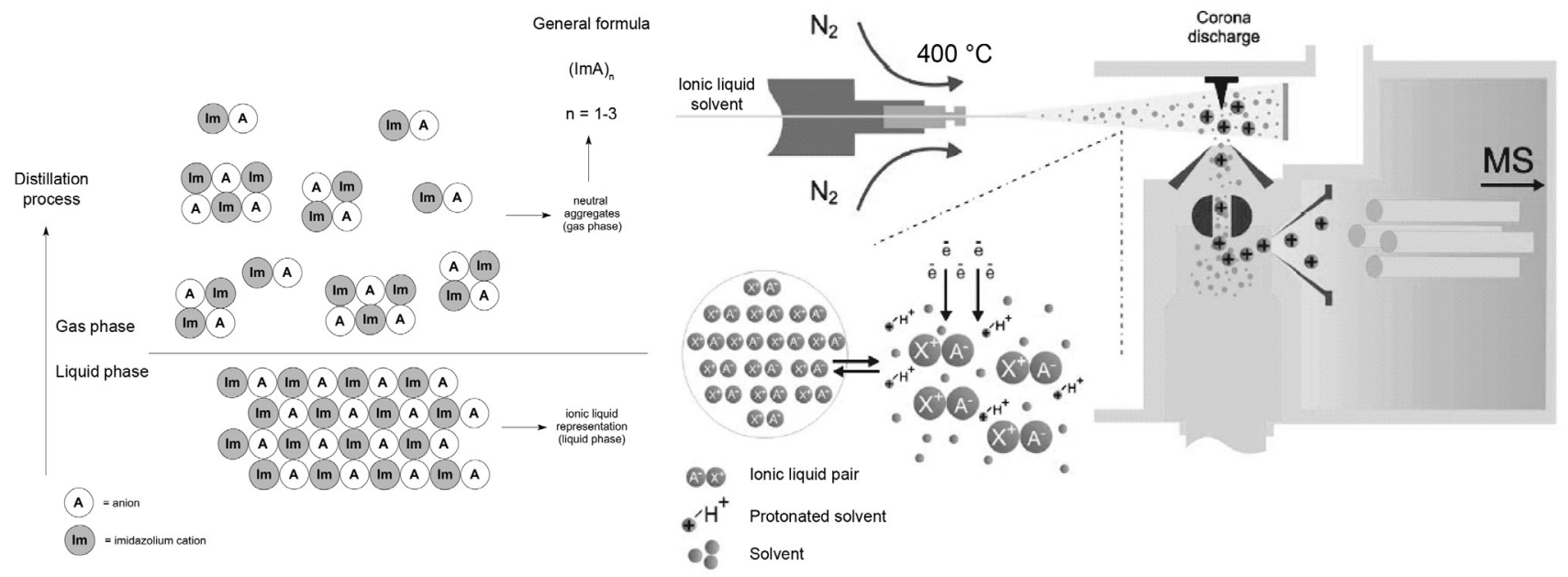

Scheme 2. Plausible distillation process of imidazolium-based ionic liquids (left) and the APCI-MS(/MS) process (right). Adapted from reference 19.

process. Carbene formation and a proton transfer mechanism cannot be discarded, but the evidence points towards neutral aggregates during the vaporization. The tested chiral $^{20}$ and functionalized IL $\mathbf{6}$ showed a similar behavior during the distillation process, thus it indicates that other functionalized (chiral or not) ILs may undergo distillation through the same mechanism. Also, we can note the presence of a methyl group in the $\mathrm{C} 2$-position of the imidazolium ring (ILs $\mathbf{1}$ and $\mathbf{2}$, see Figure 1) to avoid carbene formation even though, the IL is distilled.

In imidazolium-based ILs, as a consequence of the relative acidity of their $\mathrm{C} 2-\mathrm{H}$ hydrogens ( $\mathrm{pKa}$ on the range of 21-23), ${ }^{21} \mathrm{~N}$-heterocyclic carbenes (NHC) may coexist and are, therefore, believed to act as key species. Indeed, they exert a major influence on some major IL properties and are capable of stabilizing metal complex derivatives and metal nanoparticles, and, in some cases, NHC are capable of acting as catalysts for reactions performed in "noninnocent" ILs. There have been, however, controversial evidences that $\mathrm{NHC}$ co-exists in pure liquids or solutions with the parent imidazolium ions. Actually, many authors remain skeptical about the role of NHC in IL chemistry, particularly in protic solvents. ${ }^{22}$
With this in mind, we have synthesized a di-charged imidazolium-based nickel-containing IL with high crystalline organization (Scheme 3 ) to a mass spectrometry (MS) study, ${ }^{23}$ mostly based on electrospray ionization tandem mass spectrometry ESI-MS(/MS).

The di-charged Ni-containing IL displayed a wellorganized 3D network and formed well-ordered ionic channels (Figure 2). It is noted that both imidazolium rings are directed to the nickel-containing anion.

NHC are neutral species. A major limitation of MS is that this technique is blind to neutral entities. Nevertheless, the second imidazolium in the structure of IL $\mathbf{8}$ can act as a charge-tag, thus allowing the detection and characterization of the carbene, as shown in Scheme 4.

Note that without the charge-tag, it would not be possible the detection and characterization of the NHC with a $m / z 235$. This successful idea was later fully explored by Corilo et al. ${ }^{24}$ to probe the NHC formation in doubly, triply and quadruply charged imidazolium derivatives. Despite the good results obtained with the strategy of a positive charge-tag, the possibility that NHCs were formed in the gas phase from a direct reaction of the imidazolium and the anion could not be completely

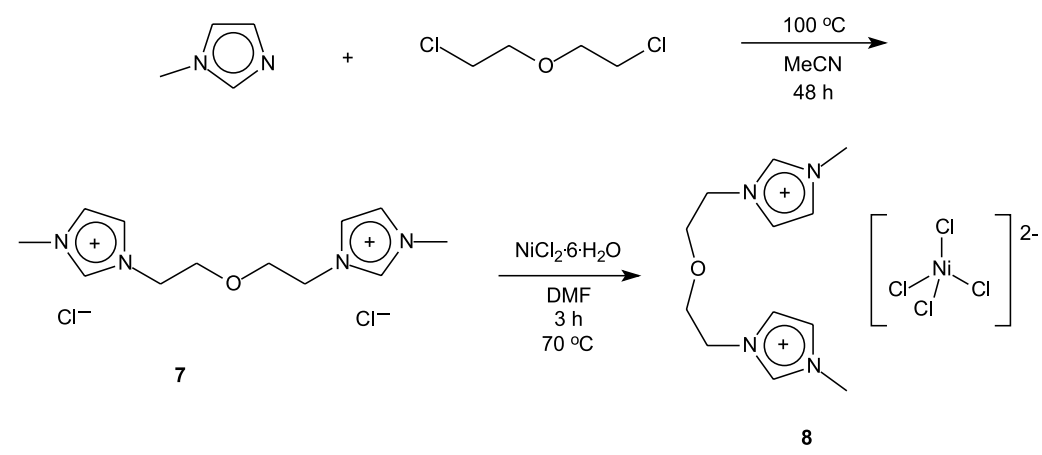

Scheme 3. Synthesis of the di-charged Ni-containing ionic liquid. 
dismissed.

Since the strategy of using charge-tags is very

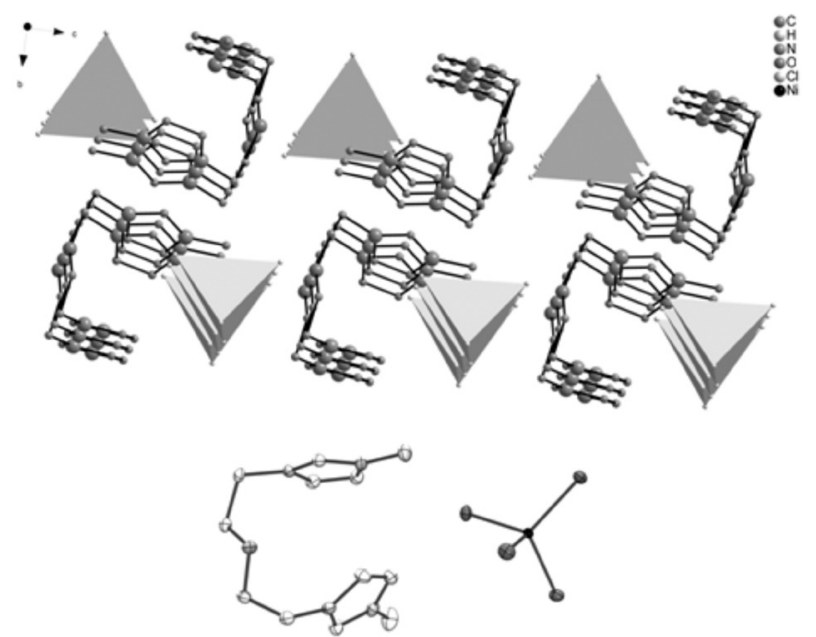

Figure 2. View of the crystal structure of $\mathbf{8}$ along the crystallographic $a$ axis (top). $\left[\mathrm{NiCl}_{4}\right]^{2-}$ anions are shown as tetrahedral. Ionic pair of the di-charged cation and the metal-containing anion (bottom). Hydrogen atoms have been omitted for clarity in both cases. X-ray originally published in reference 23. promising and the study in the positive ion mode (ESI(+)-MS/MS) does not discard the possibility of NHC formation in a gas phase reaction, we decided to study the NHC formation in the negative ion mode by using a negative charge-tag instead of a positive one. ${ }^{25}$ Thus, two imidazolium derivatives were synthesized with the possibility of forming a negative charge in the side chain of their structures (Scheme 5).

The presence of a negative charge-tag in both NHC $11(m / z, 139)$ and NHC $12(m / z, 203)$, allowed the detection and characterization by ESI(-)-MS/MS. Moreover, the study was conducted in a protic solvent (i.e., methanol) to show that even in protic solvent NHCs can co-exist under many conditions. ESI was, in this case, an excellent choice since it is a technique capable of a gentle "fishing" of the ions from the solution directly into the gas phase. ${ }^{26}$ Fortunately, the strategy proved to be valuable and both NHCs (11 and 12) were detected and characterized. To be sure about their formation, both NHCs were also promptly reacted with $\mathrm{CO}_{2}$ in the gas phase. The ion/

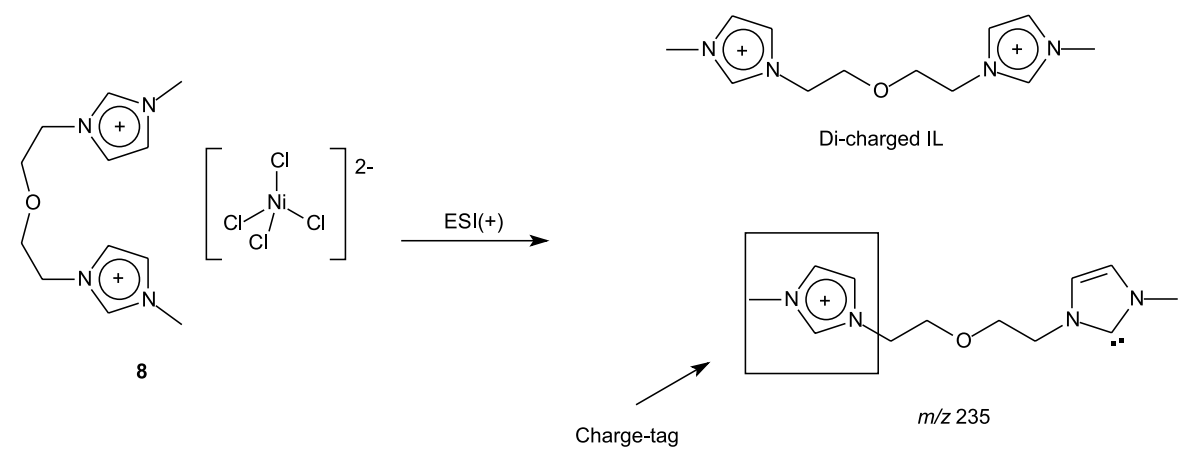

Scheme 4. Charge-tagged $N$-heterocyclic carbenes (NHC) of $\mathrm{m} / \mathrm{z} 235$.<smiles>CN(CC(=O)O)C(=O)c1nccn1C</smiles>
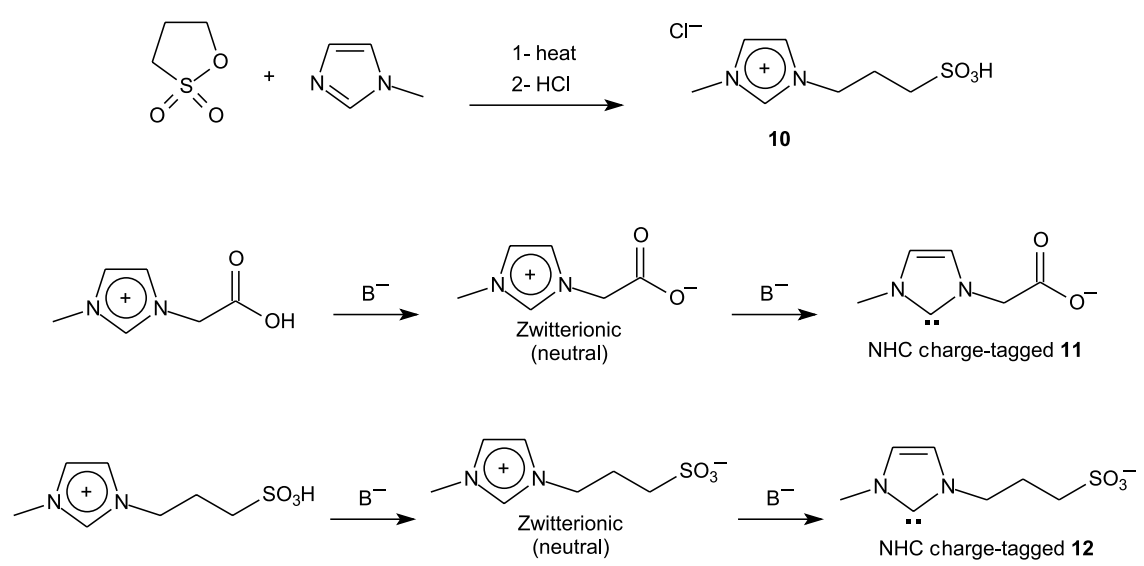

Scheme 5. Syntheses of two imidazolium-based ionic liquids as the precursors of negative charge-tagged carbenes and carbene formation. 
molecule reactions, which is a very elegant way to confirm the proposed structures, resulted in the direct addition of NHC to $\mathrm{CO}_{2}$ (Scheme 6), thus confirming the interception of the NHC species.

Indeed, all results opened up a new avenue for the intrinsic physicochemical properties evaluation and the solvent/counter-ion reactivity of many types of reactants with gaseous NHC from imidazolium derivatives, which are now possible, based on the strategy of negative charge-tags.

\section{Supramolecular Aggregates (and Ion-Pairing) Formation: the Ionic Liquid Effect}

The capacity of forming supramolecular aggregates with both cations and anions allows the possibility of stabilizing charged and polar intermediates (or transition states) of many kinds of reactions by using ILs as the media.

In this sense, the ionic nature of the intermediary species in the Baylis-Hillman reaction (BHR) render them as an attractive model for studying the effect of ionic media on both the stability and reactivity of such intermediates, as shown in the commonly accepted mechanism for the BHR (Scheme 7).

Indeed, the use of ESI-MS allowed us to detect and characterize the supramolecular aggregates from the BHR (Figure 3). ${ }^{27}$

These unprecedented supramolecular species (Figure 3) detected by both modes ESI(+)MS(/MS) and ESI(-)MS(/MS) allowed a better understanding on how imidazolium-based ILs could help in the formation and stabilization of the charged intermediates from the BHR. Those ILs were capable of participating as supramolecular coordination species resulting in more stable intermediates. Moreover, we proposed the aldehyde activation toward nucleophilic attack via 1-n-butyl-3-methylimidazolium (BMI) coordination (Scheme 8).

We have also studied the ionic liquid effect in intermolecular hydroamination or hydroarylation reactions of norbornene and cyclohexadiene performed with catalytic amounts of Brønsted or Lewis acid in imidazolium ILs (Scheme 9). ${ }^{28}$ It is worth remembering that Brønsted acids commonly display superacid behavior in ILs, as reviewed elsewhere. ${ }^{29}$

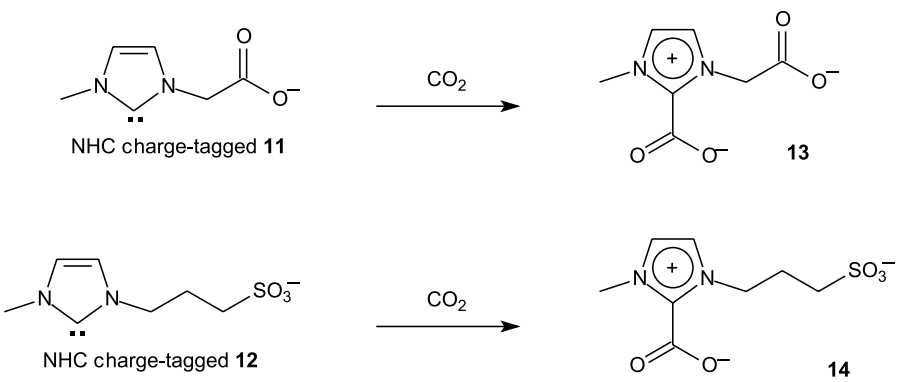

Scheme 6. Ion/molecule reactions in the gas phase of the negative-charge tagged $N$-heterocyclic carbenes $\mathbf{1 1}$ and $\mathbf{1 2}$ with $\mathrm{CO}_{2}$ generating $\mathbf{1 3}(\mathrm{m} / \mathrm{z}, 183)$ and $14(\mathrm{~m} / \mathrm{z} 247)$.

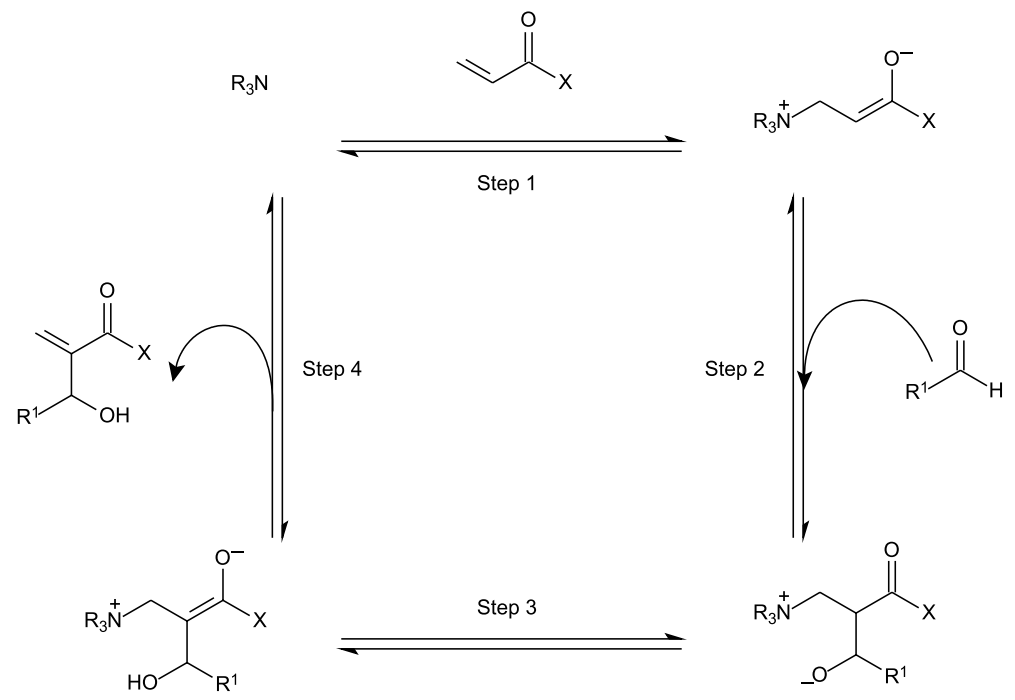

Scheme 7. Accepted basic mechanism for the Baylis-Hillman reaction. 


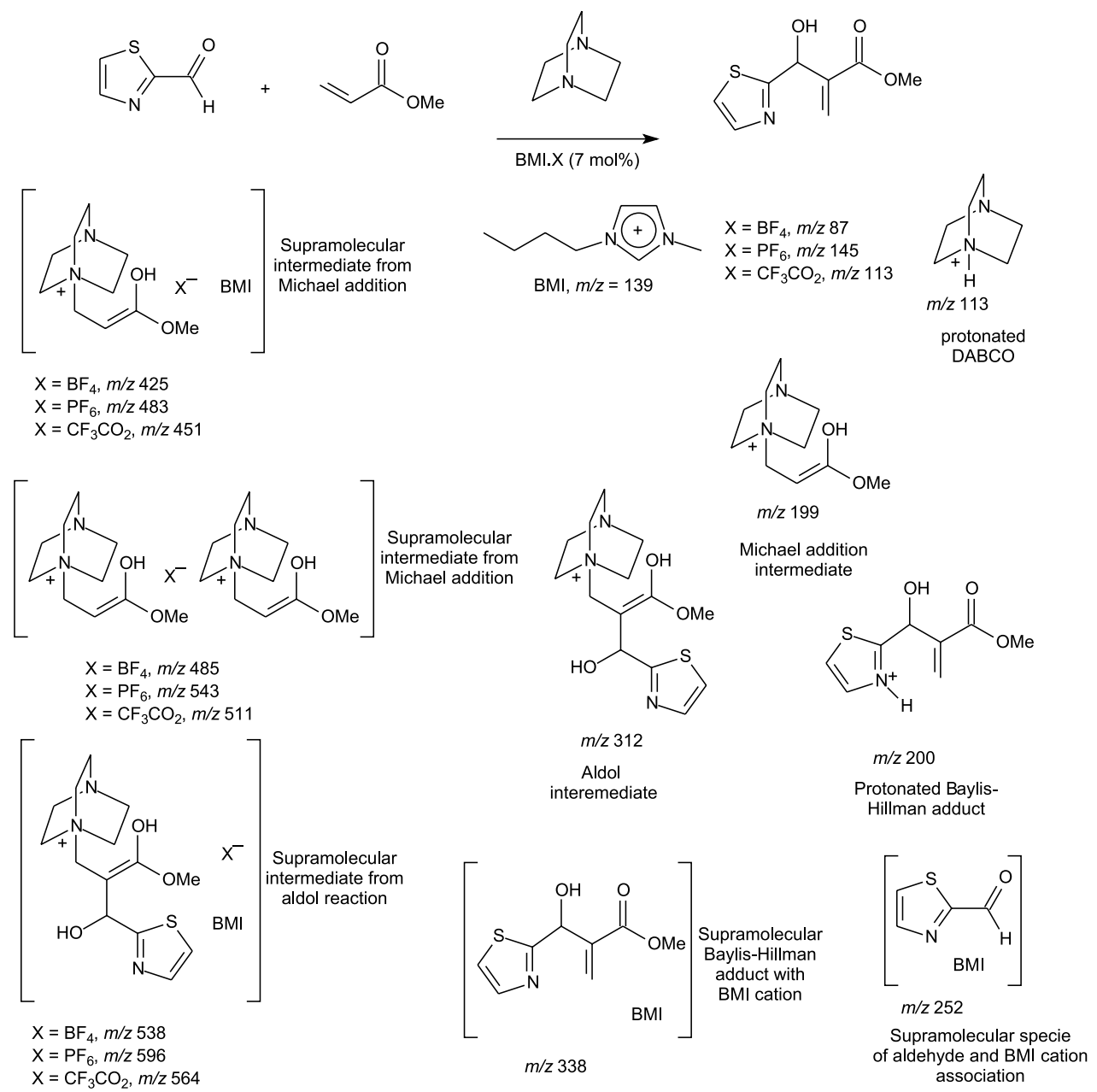

Figure 3. Supramolecular aggregates of charged intermediates from the Baylis-Hillman reaction with imidazolium-based ionic liquids detected and characterized by ESI-MS(/MS).

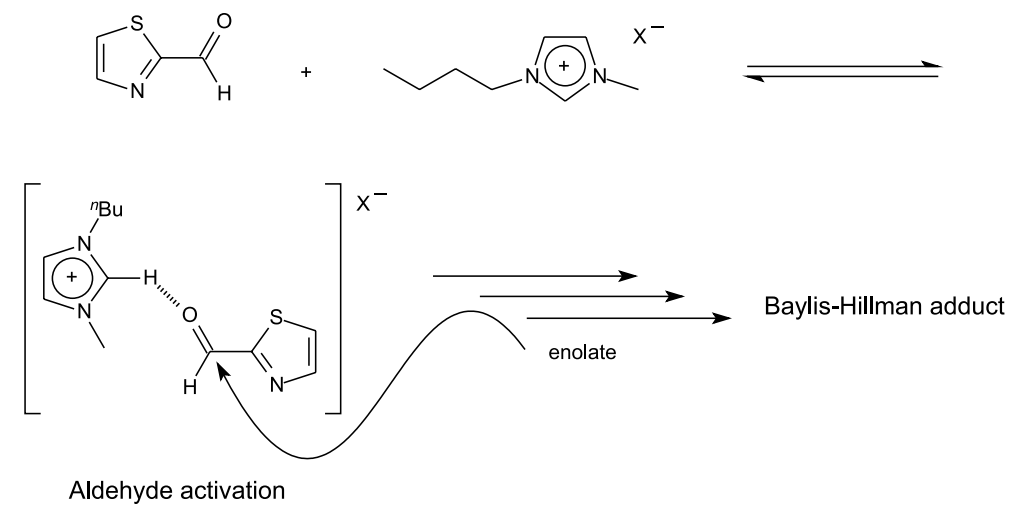

Scheme 8. Aldehyde activation by 1-n-butyl-3-methylimidazolium cation.

Results showed higher selectivity and yields for those reactions performed in ILs than those performed in classical organic solvents. The IL increases the acidity of the media and stabilizes ionic intermediates through the formation of supramolecular aggregates. The presence of charged intermediates is clear from Scheme 9 in the proposed mechanism. It is also possible to observe that the anion may play a role in the stabilization of these intermediates. In fact, it was possible to conclude that anions with low coordination ability (related to the basic character of the anion and the ionicity of the molten salt), i.e., such as $\mathrm{NTf}_{2}$, gave better results for the reaction. ILs not only increased the acidity of the media, especially of the anilinium salt, but also stabilized the key intermediate ionic species via the formation of 

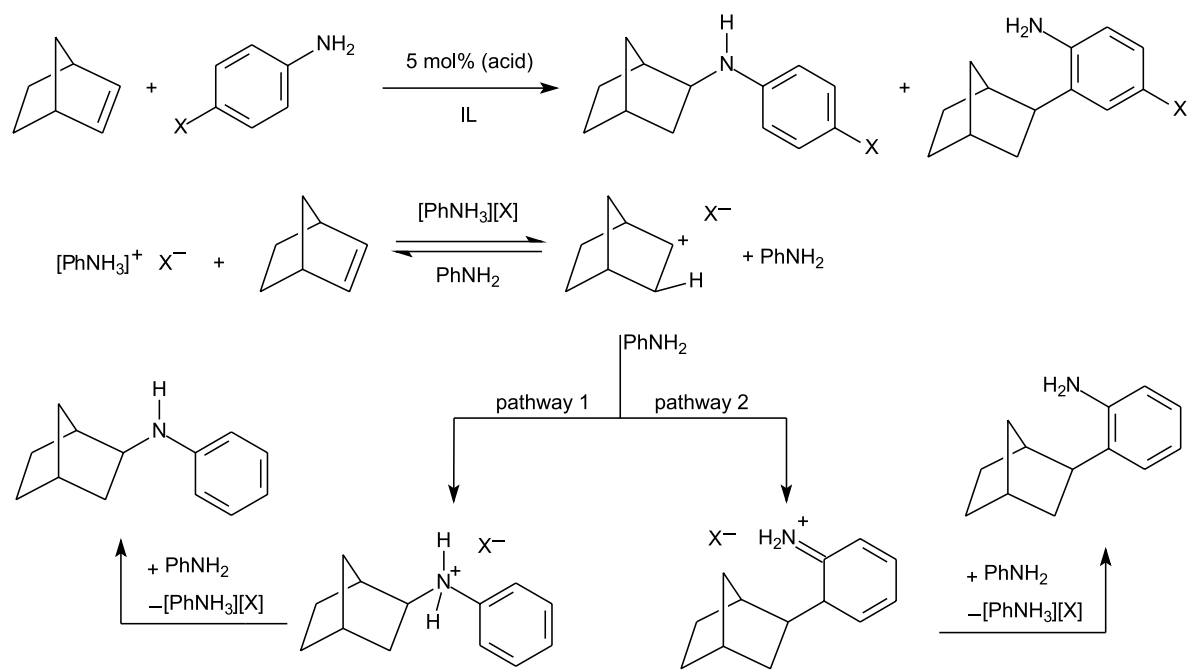

Scheme 9. Hydroamination/hydroarylation reactions in ionic liquids and proposed acid catalyzed reaction pathway. Adapted from reference 28.

supramolecular aggregates. In ionic media, it was also possible to tune the selectivity for $\mathrm{N}-\mathrm{H}$ or $\mathrm{Ar}-\mathrm{H}$ products by changing the reaction conditions and aniline substitution patterns. Supramolecular aggregates were detected and characterized by $\mathrm{ESI}(+)-\mathrm{MS}(/ \mathrm{MS})$, demonstrating the ability of the anion to stabilize the charged intermediates formed during the transformation. Indeed, the ionic liquid effect resulted in much better yields and selectivity when compared to those in classical molecular solvents. Figure 4 shows the detected supramolecular aggregates.

\section{Catalysis in Imidazolium-Based lonic Liquids}

ILs are very attractive media to promote catalytic reactions. Their negligible vapor pressure, capacity

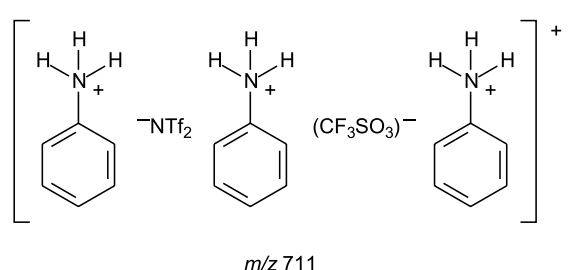

$m / 2711$

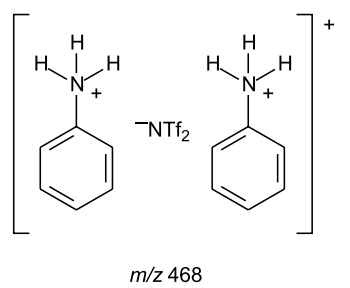

to solubilize a wild range of organic, inorganic and organometallic compounds, tuned miscibility (or immiscibility) with a plethora of solvents, and tuned physicochemical properties make ILs an extremely attractive media to promote a wild range of catalytic reactions. Moreover, in many cases, it is interesting to note the formation of two-phase catalytic systems, which are commonly observed in catalysis promoted in ILs. Many recently reviews describe some aspects of the advances made in IL-mediated catalysis. ${ }^{30-32}$

Considering all these attractive features of imidazolium ILs, they were thought as alternatives to organoaluminate melts, which were prepared upon mixing of quaternary ammonium salts (e.g. $N$-alkylpyridinium or 1,3-dialkylimidazolium halides) with $\mathrm{AlCl}_{3}$ in different

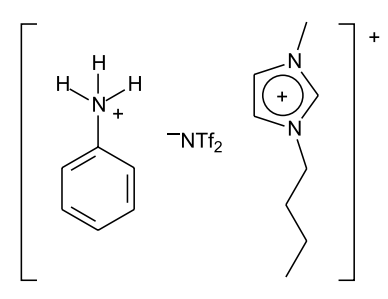

$m / z 513$

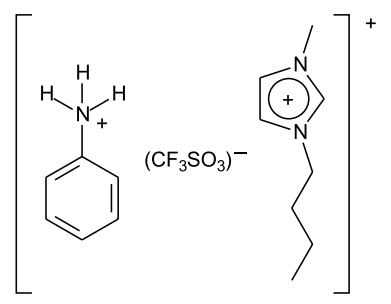

$m / z 337$

Figure 4. Supramolecular aggregates of charged intermediates from hydroamination (or hydroarylation) reaction with imidazolium-based ionic liquids detected and characterized by ESI-MS(/MS). 


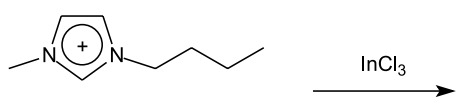

$\mathrm{Cl}^{-}$

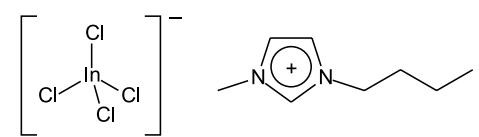

Scheme 10. Synthesis of the organoindate ionic liquid BMI.InCl 4 .

proportions. However, these compounds are reactive towards air and moisture. Moreover, they are difficult to handle and several organic/organometallic substrates are not chemically inert in these media. These major drawbacks limit their application, especially as recyclable media. In this sense, we have developed ${ }^{33}$ a novel organoindate room temperature IL (Scheme 10) to overcome these limitations.

The new IL BMI. $\mathrm{InCl}_{4}$ displayed relative low viscosity, was easy to handle, air stable and not moisture sensitive. The new ionic liquid was applied in the tetrahydropyranylation of different alcohols (Scheme 11) and it was used as the reaction media and catalyst for the reaction.

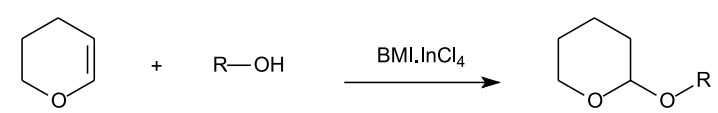

Scheme 11. Tetrahydropyranylation of alcohols in BMI. $\mathrm{InCl}_{4}$.

The system was recycled and reused five times. One impressive feature of this reaction is the product separation (Scheme 12).

Scheme 12 shows the so-called "ideal catalysis" since it is possible to recycle the catalytic system and product separation is only a decantation process. It is worth describing that only the desired product is found in the upper phase after catalysis had taken place.

The Mannich reaction and the $N$-acyliminium chemistry are very useful and can be applied in the synthesis of many alkaloids and biologically active compounds. $\mathrm{N}$-acyliminium cations can be generated in the presence of different Lewis acids. Since the IL BMI. $\mathrm{InCl}_{4}$ had already a Lewis acid character in its anion, we successfully combined such a partnership to test an in situ generation of those ions which were trapped by active olefins (Scheme 13). ${ }^{34}$

Interestingly, the use of other ILs rather than BMI.InCl

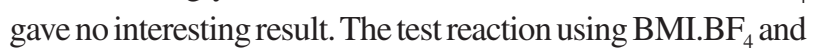

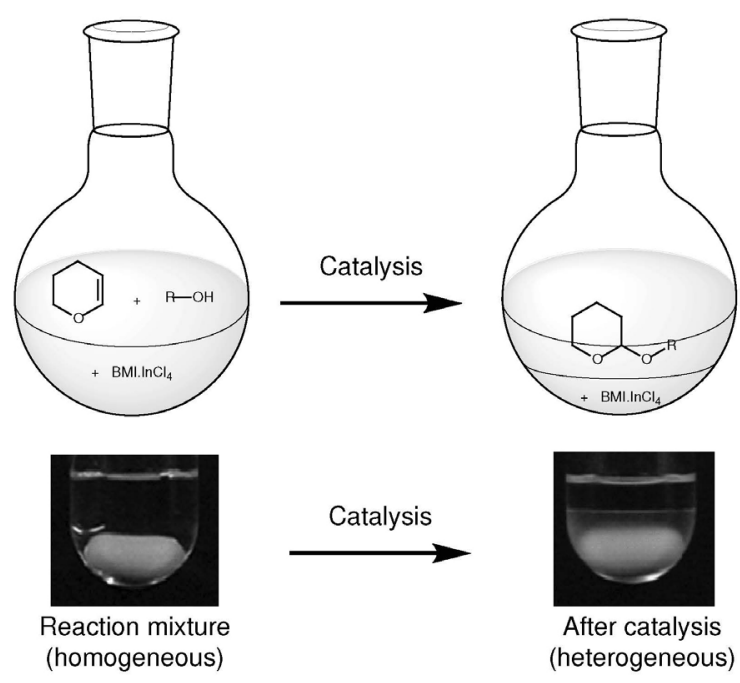

Scheme 12. A schematic (top) and an actual view (bottom) of catalytic 1-pentanol protection in BMI.InCl ${ }_{4}$ with 3,4-dihydro-2H-pyran before and after catalysis. The white bar (bottom) is the magnetic bar. Picture adapted from reference 33 .

$5 \mathrm{~mol} \%$ of $\mathrm{InCl}_{3}$ (as an additive) gave the desired product in only $25 \%$ at $50{ }^{\circ} \mathrm{C}$. On the other hand, reactions carried out in $\mathrm{BMI} . \mathrm{InCl}_{4}$ without any additive, resulted in compound $\mathbf{1 7}$ in $80 \%$ at room temperature $\left(25^{\circ} \mathrm{C}\right)$. The diastereoselectivity of the reaction was evaluated using $Z$-olefins and gave very good results. All diastereoselectivities ranged from 5:1 to 12:1 favoring the erythro isomers.

Another application of BMI. $\mathrm{InCl}_{4}$ was to support different metal catalysts to promote biodiesel synthesis. We have used this IL as support with impressive results. ${ }^{35}$ The best catalyst among the 28 tested was $\mathrm{Sn}$ (3-hydroxy2-methyl-4-pyrone $)_{2}\left(\mathrm{H}_{2} \mathrm{O}\right)_{2}$ supported in $\mathrm{BMI}^{-\mathrm{InCl}_{4}}$ to perform the transesterification reaction of soybean oil (Scheme 14).

We found that the biodiesel yield increased from

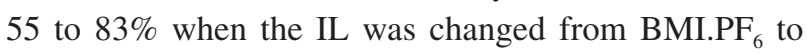
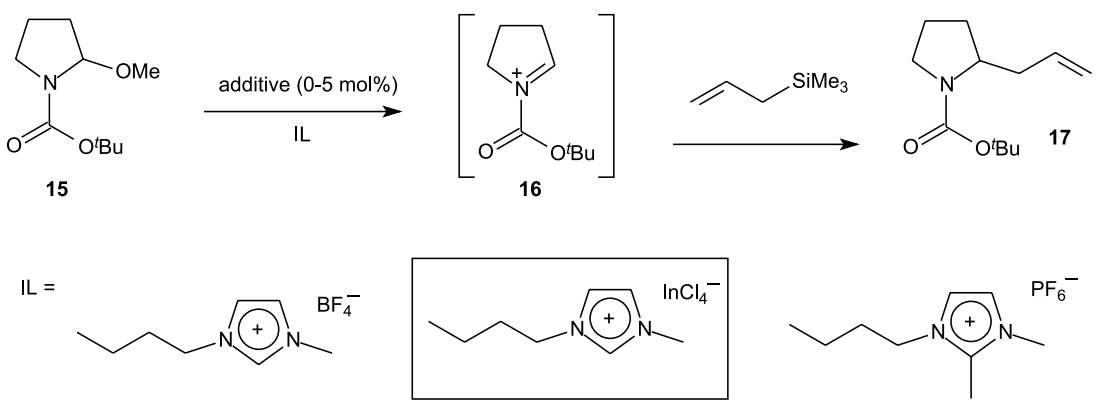

Scheme 13. $N$-acyliminium ions generation and reactions in $\mathrm{BMI} . \mathrm{InCl}_{4}$. 

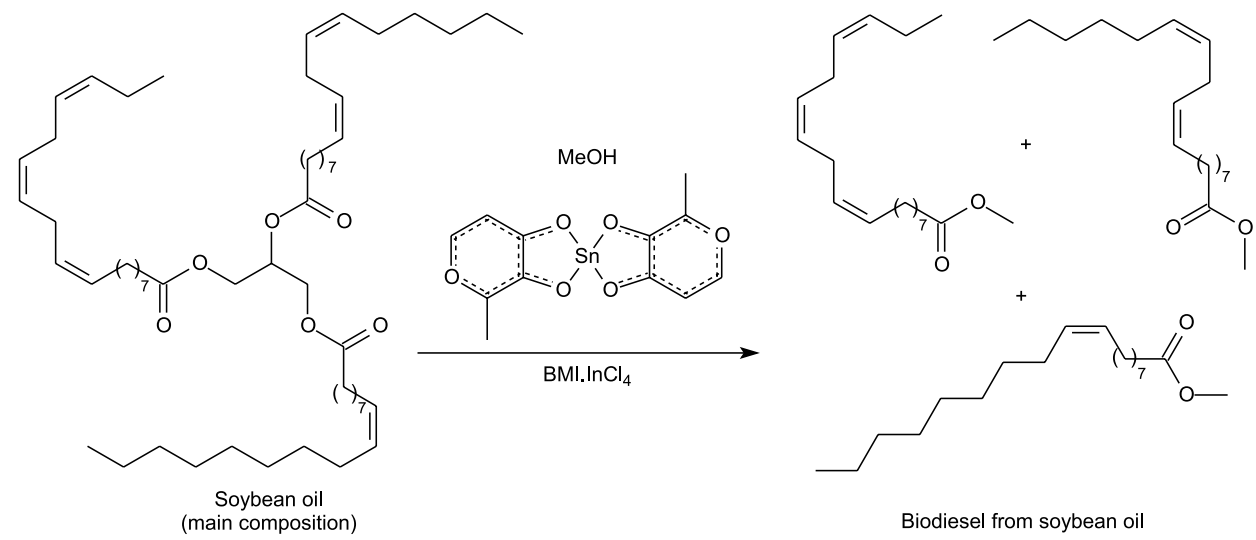

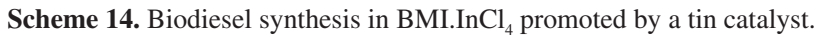

BMI.InCl ${ }_{4}$ within just $4 \mathrm{~h}$. After this time, yields decrease as a consequence of a reverse transesterification with the formed glycerol. We have also showed that the catalytic system was active for a direct esterification reaction. Based on all obtained results, the mechanism could be studied and a catalytic cycle for the transformation was proposed (Scheme 15).
Upon methanol addition, the catalytically active species $\mathbf{2 0}$ is formed in situ through a ligand exchange. Thus, the coordination of the triglyceride (or diglyceride, monoglyceride or the fatty acid) takes place forming the intermediate 21. As a consequence, the natural polarization of the $\mathrm{C}=\mathrm{O}$ bond increase, facilitating the next step, i.e., the nucleophilic attack of the alcohol. After that, species 21<smiles>CC1OCCC2O[Si]3(OC4CCOC(C)C4O3)OC12</smiles>

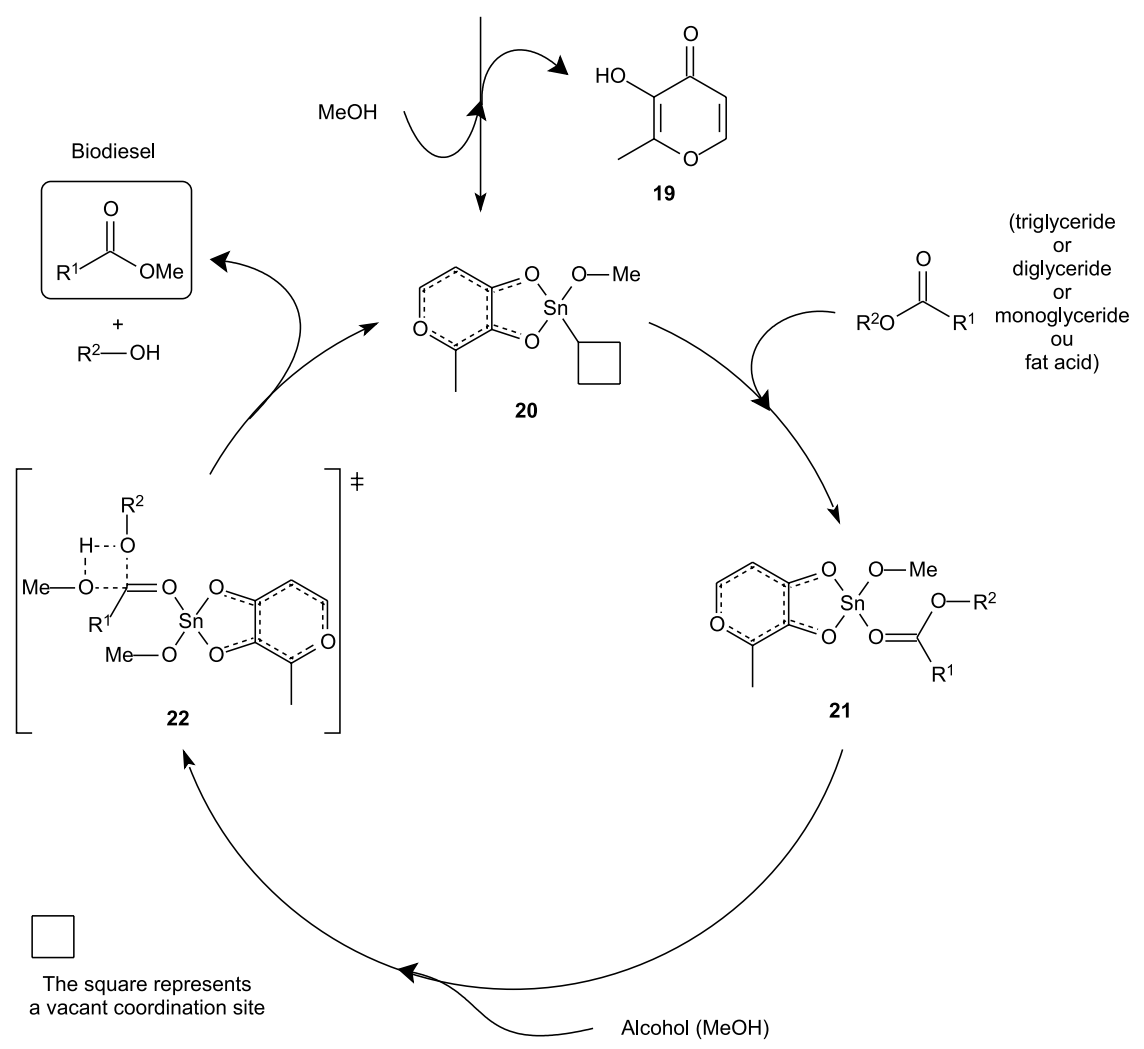

Scheme 15. Catalytic cycle proposed for the transesterification or direct esterification furnishing biodiesel. Adapted from reference 35 . 
probably develops via a four center transition state $\mathbf{2 2}$ furnishing the desired biodiesel, as shown in Scheme 15.

Commonly used ILs were also tested as support to classic acid and base catalyzed synthesis of biodiesel. We showed the efficiency of the catalytic system with $\mathrm{K}_{2} \mathrm{CO}_{3}$ (basic catalysis) and $\mathrm{H}_{2} \mathrm{SO}_{4}$ (acid catalysis) in those ILs. ${ }^{36}$ The biodiesel could be obtained in almost quantitative yields in less than $1 \mathrm{~h}$. One interesting feature of the article was the study on carbene formation in BMI.NTf ${ }_{2}$, since there was the presence of basic species to promote the biodiesel synthesis. By using ${ }^{13} \mathrm{C}$ NMR, we could observe that the presence of ethanol inhibited the carbene formation (Figure 5).

It is noted that the addition of a base resulted in a drastic reduction of the $\mathrm{C} 2$ carbon intensity in the ${ }^{13} \mathrm{C}$ spectrum indicating carbene formation. In the presence of ethanol, the signal increases again, indicating that the carbene may form, but the presence of an acidic hydrogen in the alcohol allows an immediate protonation.

Biodiesel, despite being a promising alternative fuel, has many technological problems associated with its use. ILs, however, have proven to be an excellent media for the synthesis and modification of this biofuel, as recently reviewed. ${ }^{37-40}$ In this sense, we decided to perform an enzymatic modification of biodiesel towards a better oxidative stability of the biofuel. ${ }^{41}$ We have tested 9 commercially available lipases to promote the epoxidation of $\mathrm{C}=\mathrm{C}$ bond of methyl oleate using hydrogen peroxide as the oxidizing agent (Scheme 16).

Interestingly, the three tested ILs (BMI.PF 6 , BMI.NTf ${ }_{2}$ and $\mathrm{BMI}_{\mathrm{B}} \mathrm{BF}_{4}$ ) gave very different results. The use of hydrophobic ILs (BMI.PF ${ }_{6}$ and BMI.NTf ${ }_{2}$ ) gave the desired epoxidized methyl oleate (EMO) in good yields.
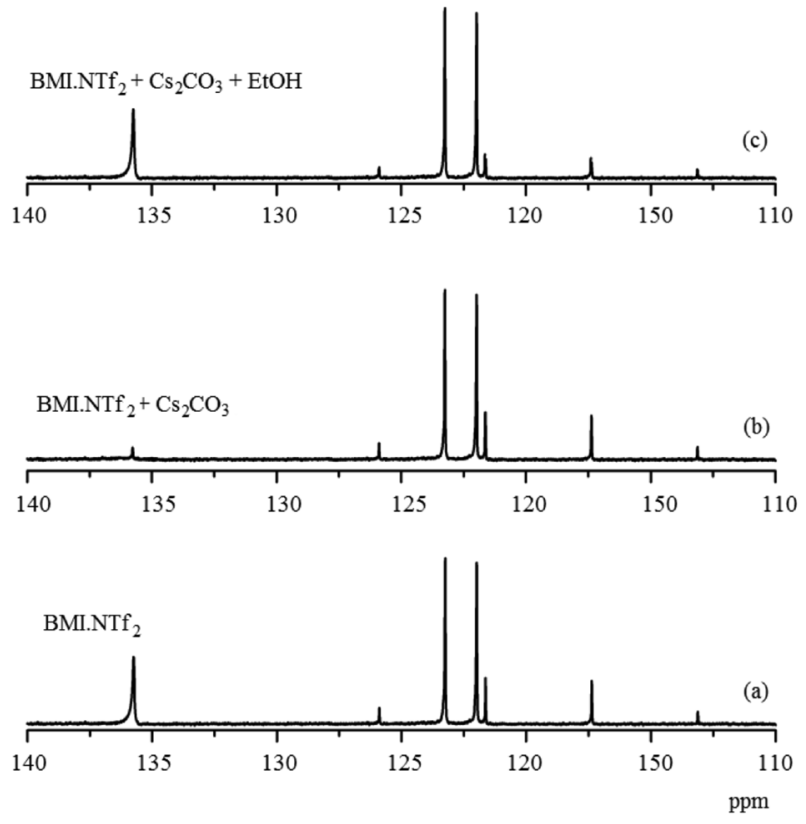

Figure 5. ${ }^{13} \mathrm{C}-\left\{{ }^{1} \mathrm{H}-\mathrm{NMR}\right.$ experiments at $70{ }^{\circ} \mathrm{C}$. Experiments conducted in a sealed NMR tube containing a sealed capillary tube charged with DMSO- $d_{6}$ as the external scale reference. Note the quartet of the $\mathrm{CF}_{3}$ of the anion. (a) Pure ionic liquid BMI.NTf 2 , (b) BMI.NTf and $\mathrm{Cs}_{2} \mathrm{CO}_{3}$ and (c) BMI.NTf ${ }_{2}, \mathrm{Cs}_{2} \mathrm{CO}_{3}$ and EtOH. Reproduced from reference 36 by permission of Wiley-VCH Verlag GmbH\& Co. KGaA, Weinheim.

However, in $\mathrm{BMI}_{\mathrm{P}} \mathrm{PF}_{6}$, the best enzyme was R Amano $\mathrm{K}$ (from Penicillium roqueforti) which resulted in EMO in $82 \%$ in the fifth reaction hour. In the mean time, the best enzyme in BMI.NTf ${ }_{2}$ was lipase type II (from calf tongue roof), resulting in EMO in 78\% in the first hour of reaction. It was also observed low yields of DIOL with those two ILs. The use of a hydrophilic IL, however, gave the most surprising and impressive result. In the first hour of reaction, only EMO was obtained in $89 \%$ by using lipase Amano A
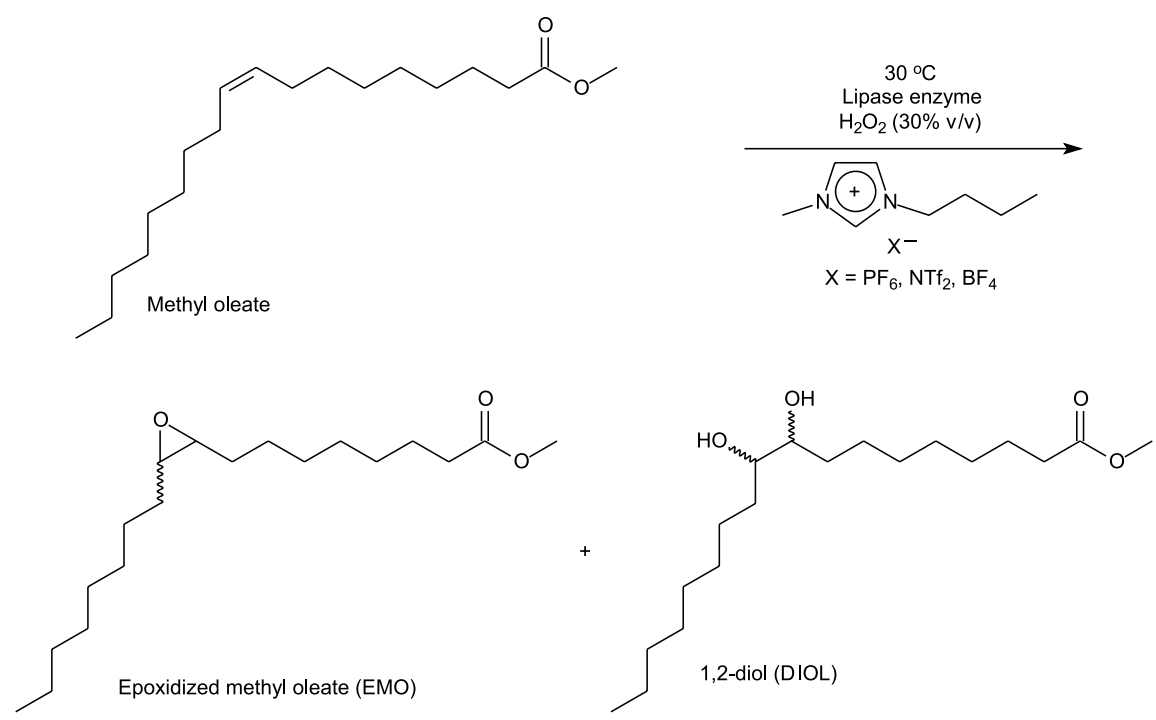

Scheme 16. Enzyme- (lipase-) catalyzed epoxidation (EMO) and epoxy ring-opening (DIOL) reaction using methyl oleate as the substrate and hydrogen peroxide $(30 \% \mathrm{v} / \mathrm{v})$ in ionic liquids at $30^{\circ} \mathrm{C}$. 
(from Aspergillus niger). After this time, the DIOL yield increased as well, as observed in Figure 6. We monitored the reaction for $5 \mathrm{~h}$ using lipase Amano A.

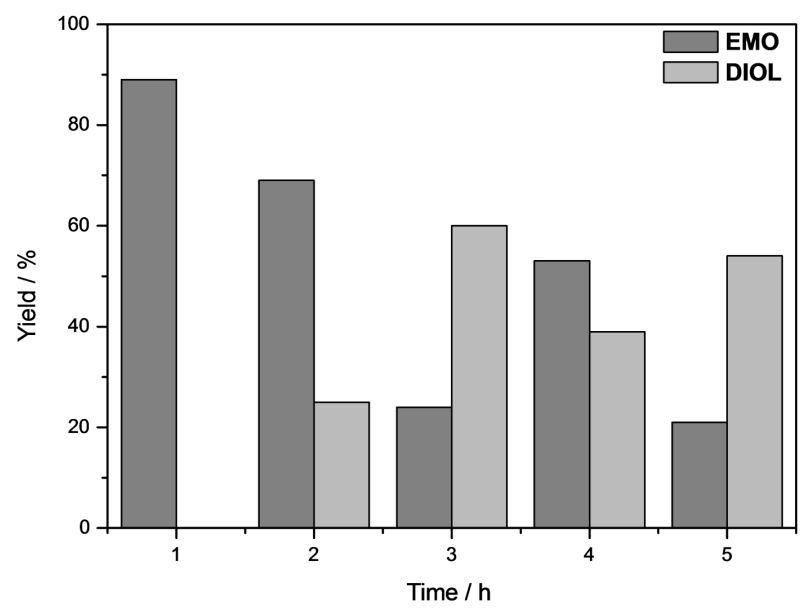

Figure 6. Obtained yield of EMO and DIOL in the first and in the fifth reaction hours under the studied conditions using ${\mathrm{BMI} . \mathrm{BF}_{4}}_{4}$ at $30^{\circ} \mathrm{C}$.

The best DIOL yields were observed in $\mathrm{BMI} \mathrm{BF}_{4}$ too. The hydrophilic character of this IL allowed a better dissolution of the oxidant agent $\left(\mathrm{H}_{2} \mathrm{O}_{2}\right)$ in the reaction media. In the third reaction hour, DIOL was obtained in $60 \%$ (the best DIOL yield among the tested ILs).

ILs can be used as efficient media to support and stabilize metal nanoparticles and this subject has been reviewed. ${ }^{42-45}$ In this sense, we have tested in situ generated palladium nanoparticles stabilized in BMI.PF ${ }_{6}$ and ${\mathrm{BMI} . \mathrm{BF}_{4}}_{4}$ to promote the selective and partial hydrogenation of biodiesel ${ }^{46}$ envisaging an increase in its oxidative stability.

The use of imidazolium-based ILs allowed the formation of ca. $5 \mathrm{~nm}$ palladium nanoparticles. Indeed, the catalytic system proved to be the most selective and efficient system for performing the selective hydrogenation of biodiesel towards oleic composition of the final product. This effect was attributed to the solubility of mono-enes and dienes in ILs. It is known that commonly dienes have a high solubility in ILs when compared to mono-enes. Thus, a mechanism to the partial hydrogenation could be proposed, as shown in Scheme 17.

Another important feature was the transmission electron microscopy (TEM) analyses after catalysis, which revealed no particle aggregation. However, the catalytic system lost its activity upon recycling. BET analysis was then performed with very elucidative results. After the first run a specific surface area of $171.685 \mathrm{~m}^{2} \mathrm{~g}^{-1}$, a porous volume of $0.3854 \mathrm{cc} \mathrm{g}^{-1}$ and a porous size smaller than $735.8 \AA$ were noted. After the sixth run, however, a surface area of $199.615 \mathrm{~m}^{2} \mathrm{~g}^{-1}$, a porous volume of $0.4726 \mathrm{cc} \mathrm{g}^{-1}$ and a porous size smaller than $412.8 \AA$ were observed. Considering that the pore size decreasing during each runs, it was comprehensive the reason for the loss of activity of the nanostructure system. The substrate could not access the catalyst preventing the reaction from taking place, especially because biodiesel is much higher in its van der Waals volume.

Biologically active compounds, such as isatins, ${ }^{47}$ were synthesized in imidazolium-based ILs with impressive

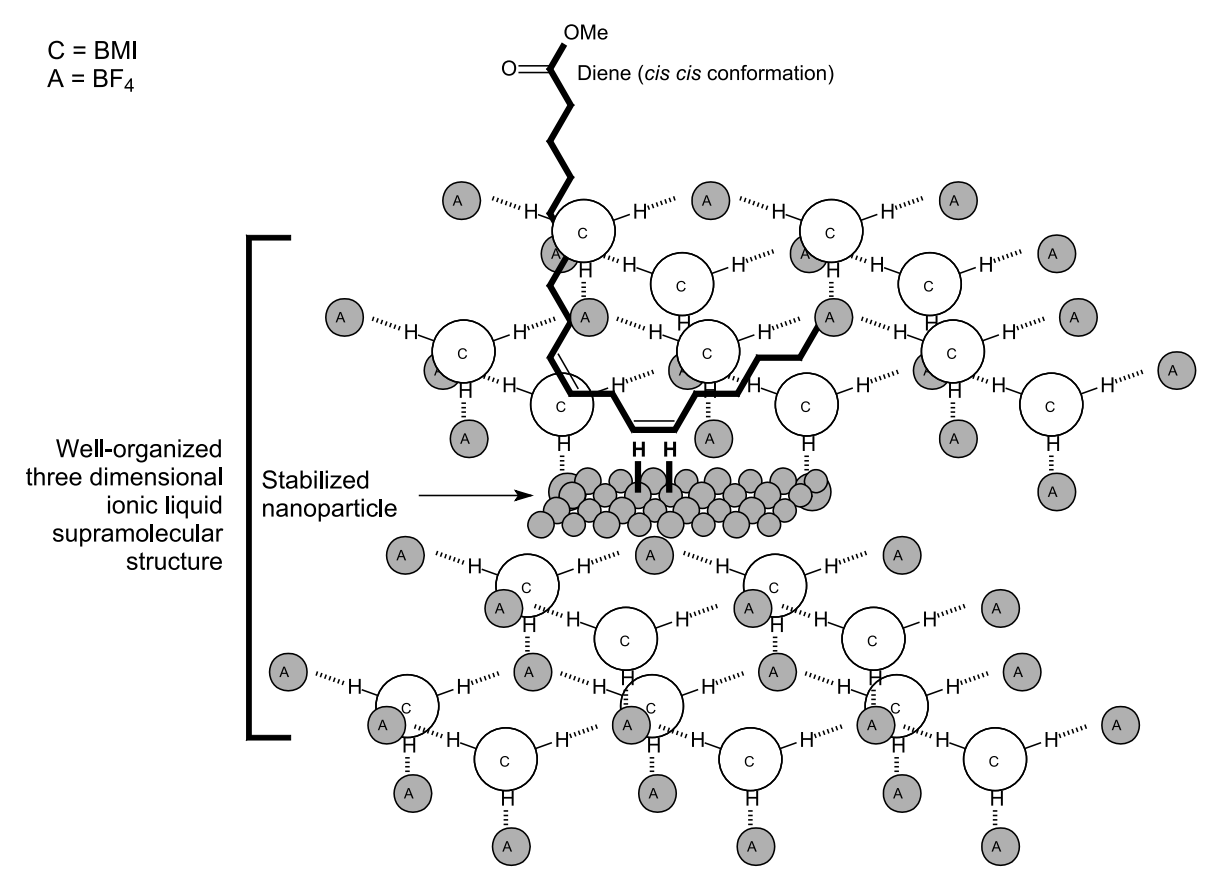

Scheme 17. Partial hydrogenation and selectivity promoted by Pd-nanoparticles in ionic liquids. Reproduced from reference 46 by permission of the Royal Society of Chemistry. 
results. Upon anion exchange, it was possible for us to obtain the isatin-3-oxime derivatives ${ }^{48}$ under acid catalysis with considerable different yields (Scheme 18).

The effect was attributed to the stabilization observed in the charged intermediates of the cyclization through ion-pairing formation, as shown in Scheme 19. The best results were obtained using BMI.NTf ${ }_{2}$ as the ionic media and $\mathrm{HBF}_{4}$ as the Brønsted acid.

Besides the anion effect, it is worth remembering that Brønsted acids have their acid strength increased in imidazolium-based ILs, ${ }^{29,49}$ as discussed before.

Amides belong to a very important class of compounds. The amide group is widespread and found in a plethora of natural products, polymers, signaling molecules and others. The class of large-chain amides is of special interest due to their biological activity. The synthesis of amides, however, is a not an easy task, as recently reviewed.$^{50}$ Envisaging an efficient methodology to obtain large-chain biomass amide derivatives, we supported some Lewis and Brønsted acids in ILs to obtain the desired product from an aminolysis reaction esters and carboxylic acids (Scheme 20). ${ }^{51}$ Reactions conducted in organic solvents (or solventless) gave only reasonable yields with longer reaction times.

All tested ILs (BMI.NTf 2, BMI.PF $_{6}$ and BMI.BF ${ }_{4}$ ) gave essentially quantitative yields using $\mathrm{BF}_{3} \cdot \mathrm{OEt}_{2}$ as the catalyst $(5 \mathrm{~mol} \%)$ and methyl oleate as the model substrate in the biphasic catalytic system. However, to avoid the anion degradation $\left(\mathrm{PF}_{6}^{-}\right.$and $\left.\mathrm{BF}_{4}^{-}\right)$, we decided to keep the study using only BMI.NTf ${ }_{2}$ as the ionic media. $\mathrm{HCl}, \mathrm{H}_{2} \mathrm{SO}_{4}, \mathrm{SnCl}_{2}$ and $\mathrm{CdO}$ gave by far the best results (ca. quantitative yields). Since we could not recycle $\mathrm{BF}_{3} . \mathrm{OEt}_{2}, \mathrm{HCl}$ and $\mathrm{H}_{2} \mathrm{SO}_{4}$, we decided to study the transformation with those two metals, i.e., $\mathrm{SnCl}_{2}$ and $\mathrm{CdO}$. Both catalysts could be used at least 8 times without

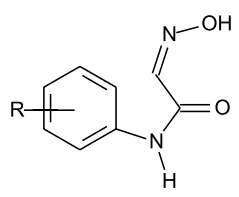

23

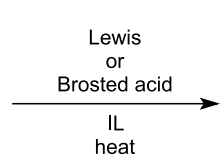

heat

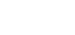

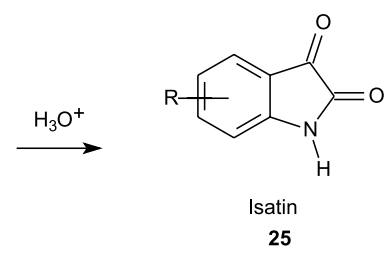

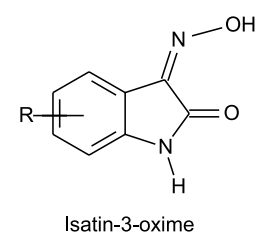

24

Scheme 18. Cyclization promoted in ionic liquids under acid conditions for the syntheses of isatin-3-oxime derivatives.<smiles>[R]c1ccc(NC(=O)/C=N/O)cc1</smiles>
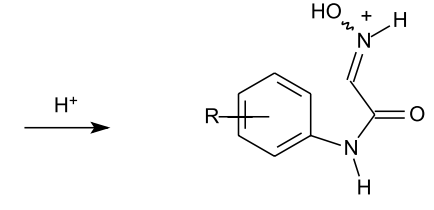

Charged intermediate

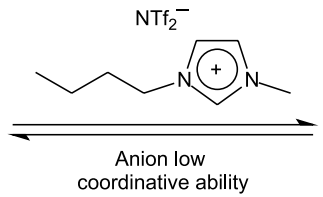

coordinative ability<smiles>[R]c1ccc(NC(=O)/C=[NH+]\O[Na])cc1</smiles>

Efficient ion-pairing

Stabilized charged intermediate
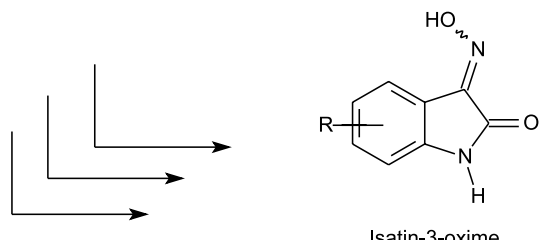

24

Scheme 19. Anion stabilizing effect of the charged intermediate during the acid $\left(\mathrm{HBF}_{4}\right)$ catalyzed cyclization in BMI.NTf . 


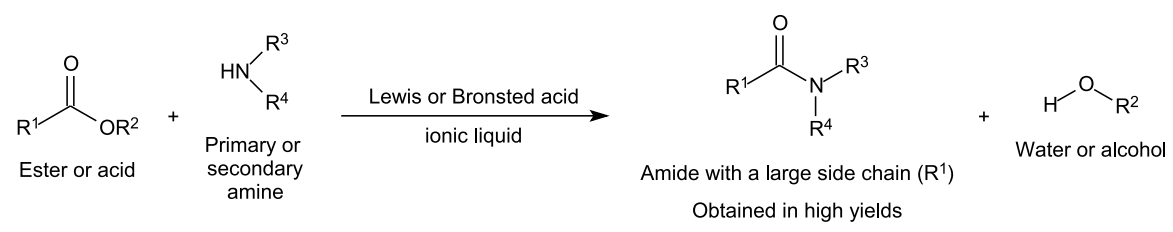

Scheme 20. General example of aminolysis reaction (amide bond formation) in ionic liquids. Note that $\mathrm{R}^{1}$ can be a large chain group.

any loss in the catalytic activity. $\mathrm{CdO}$, nevertheless, underwent leaching and $1 \%$ of the metal could be found in the product phase (upper phase). The methodology allowed the synthesis of many amide derivatives in good to excellent yields.

The mechanism of the transformation and the ionic liquid effect were studied by NMR and ESI-MS(/MS) experiments. All results allowed a better understanding on the need of amine excess in the reaction media (Scheme 21).

The obtained results indicated the preference for a 6-membered transition state, thus explaining the excess of amine in the reaction media. Moreover, the $\mathrm{C}=\mathrm{O}$ bond activation was through a cooperative mechanism of the $\mathrm{IL}$ and the metal catalyst, thus explaining the importance

(a)

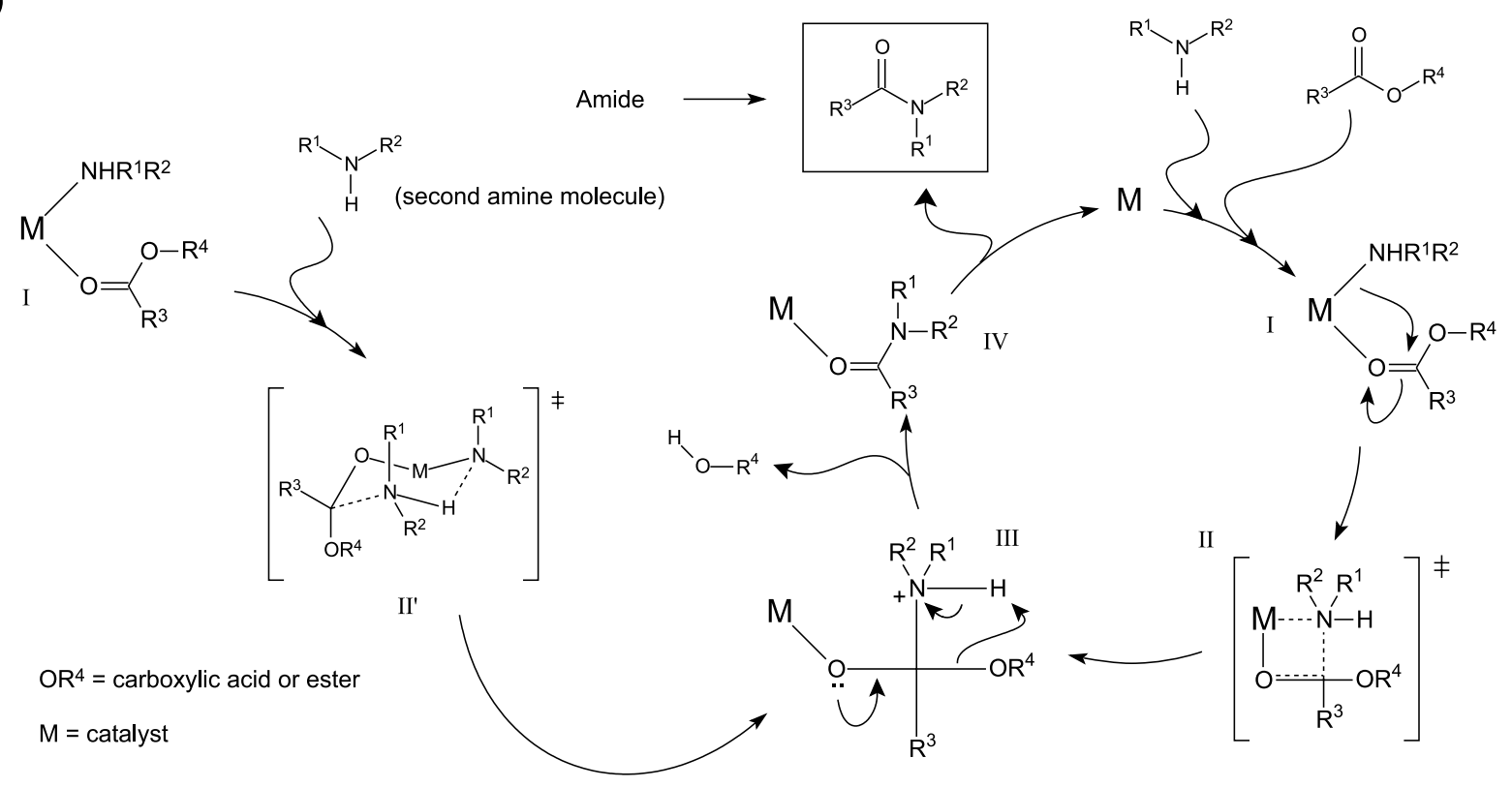

(b)
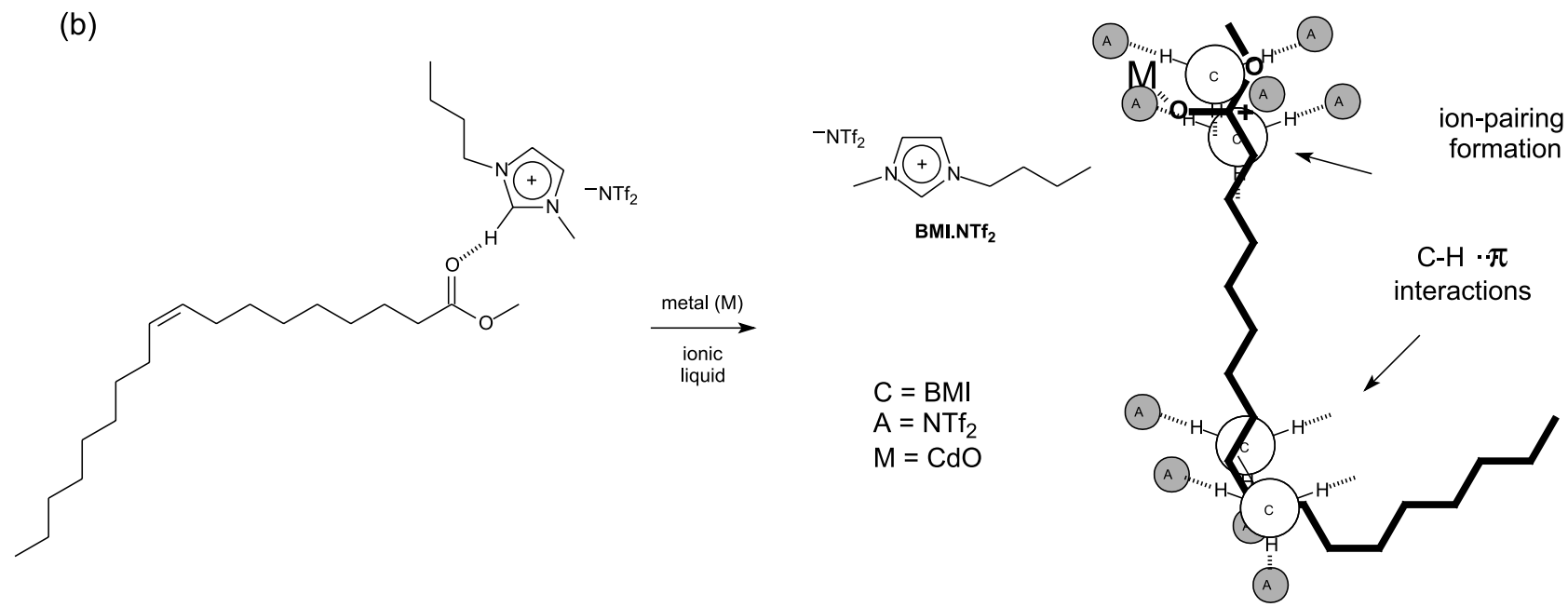

Scheme 21. (a) Plausible catalytic cycle to the aminolysis reaction in imidazolium-based ionic liquids. Note that from intermediate I the reaction can undergo through a 4-membered transition state (II) or a 6-membered transition state (II') with the participation of a second amine molecule (showed in the left side on the top of this Scheme). (b) $\mathrm{C}=\mathrm{O}$ cooperative activation in ionic liquids. Adapted from reference 51. 
of the IL in the reaction. In this case, the used IL was not only responsible for stabilize the polar and charged intermediates, but it was also responsible for a partial activation of the carbonyl group in the substrate. Due to all features studied in this transformation, it was possible to conclude that ionic liquid effect was more than just the stabilization of the charged and polar intermediates, rather the imidazolium cation also allowed a better activation of the ester (or the acid) to initiate the reaction in the presence of a metal catalyst.

\section{Catalysts with Ionic Tags}

Many advantages in the use of catalysts with ionic tags have been shown. Functionalized liquids or task-specific ionic liquids (TSILs) play a fundamental role in modern catalysis, as reviewed..$^{31,52-54}$

Envisaging a more efficient support (anchoring) in the ionic phase, ligands (and their metal derivatives) with ionic tags have been developed and tested, especially in biphasic catalysis. Aiming to achieve higher selectivities and activities (advantages of homogeneous catalysis) associate with easier product separation, catalyst recovery and reuse (advantages of heterogeneous catalysis) ILs are an obvious choice for the use of ionically-tagged catalysts. Since ILs are inherently "ionic" entities, it is more than reasonable that the tethering of an ionic tag on the catalyst structure increases the affinity (and solubility) for the IL phase. Therefore, one should expect an efficient retention of the catalyst in the ionic phase even after an extraction, thus rendering the process more environmentally benign, green, economically viable and sustainable. Moreover, an additional feature of the presence of an ionic tag is that water solubility is commonly increased, ${ }^{55}$ and it may be a desirable characteristic in many cases.

Indeed, it is interesting to rationalize some important features, principles and advantages on the use of ionicallytagged catalysts:

(i) Increased solubility in an IL phase as a consequence of the chemical affinity between the tagged ligand (or tagged metal catalyst derivative) and the ionic media.

(ii) Efficient support due to the strong interaction with the IL phase, thus avoiding the catalyst leaching and possible recovers of it.

(ii) Improvement on the catalyst physicochemical properties such as thermal stability and electrochemical window. The use of an ionic tag is an elegant and straightforward manner to tune the properties of a specific catalyst by turning it more similar to an IL.

(iii) The possibility of a nano-organization as a consequence of the ionic tag. It is worth remembering that imidazolium derivatives may act as "entropic drivers" with nano-effects and organization.

(iv) A chemical role by using catalysts with ionic tags as proposed by Lombardo and Trobini: ${ }^{53}$ "We posit as a working hypothesis that, if the tag ion pair can approach charges that develop along the reaction coordinate with minimal distortion of bond angles and distances, it can lower the free-energy barrier by complementing charge separation in the dipolar transition state. As a consequence, the catalyst loading can be reduced compared to the reference homogeneous catalyst."

(v) Orientation for the chemical approach of different reagents/reactants due the possibility of aggregate or ion-pairing formation with polar and charged intermediates. Moreover, as a consequence, the transition state of this kind of reaction is directly affected by the charge (ionic tag) in the catalyst structure. Therefore, different selectivities and yields are observed (normally both are increased).

(vi) As already described by Sebesta et al. ${ }^{54}$ " an important premise being that the ionic tag is catalytically silent and inert in reaction conditions." However, despite it is a general principle, not always it can be assumed as a true and, in some cases, the noninnocent ${ }^{56}$ nature of an imidazolium tag may be a desirable feature, as will be shown.

With all these features in mind, we have designed the synthesis and application of new catalysts with at least one ionic tag in their structure. Initially, we decided to keep the strategy of a charge tag to investigate metal complexes of palladium, copper and nickel and apply the ionically-tagged palladium complex as the promoter of phosphine-free Heck and Suzuki reactions. ${ }^{57}$

First, the known ${ }^{58}$ ionically-tagged ligand (and acetate derivative) was synthesized as shown in Scheme 22.

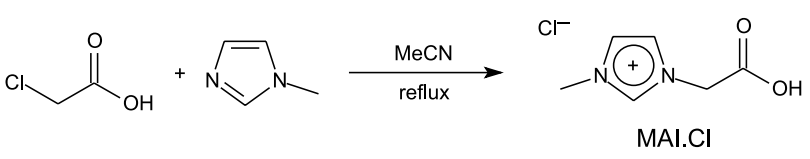

Scheme 22. Synthesis of the ionically-tagged ligand (acetate derivative) MAI.Cl.

The ligand MAI.Cl could then be treated in situ with neutral $\mathrm{Cu}(\mathrm{OAc})_{2}, \mathrm{Ni}(\mathrm{OAc})_{2}$ and $\mathrm{Pd}(\mathrm{OAc})_{2}$ to form mono(and di-)-charged complex (Scheme 23).

Studies in the gas-phase by ESI-MS(/MS) revealed a unique chemistry of this species, especially for $\mathrm{Cu}$ and $\mathrm{Ni}$ derivatives, as shown in Scheme 24.

Of great importance was the detection and characterization of the organometallic derivatives $\mathbf{2 7 a}, \mathbf{b}$. The cyclization reaction (Scheme 24, pathway A) allowed 


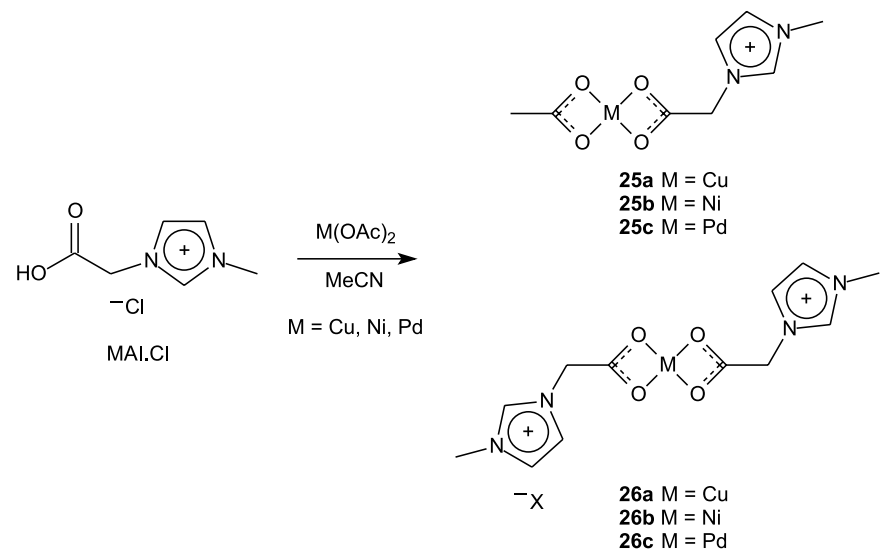

Scheme 23. In situ formation of novel metal complexes of $\mathrm{Cu}, \mathrm{Ni}$ and Pd. Note that without any anion $\left(\mathrm{X}^{-}\right)$structures $\mathbf{2 6}$ are di-charged. Adapted from reference 57 .

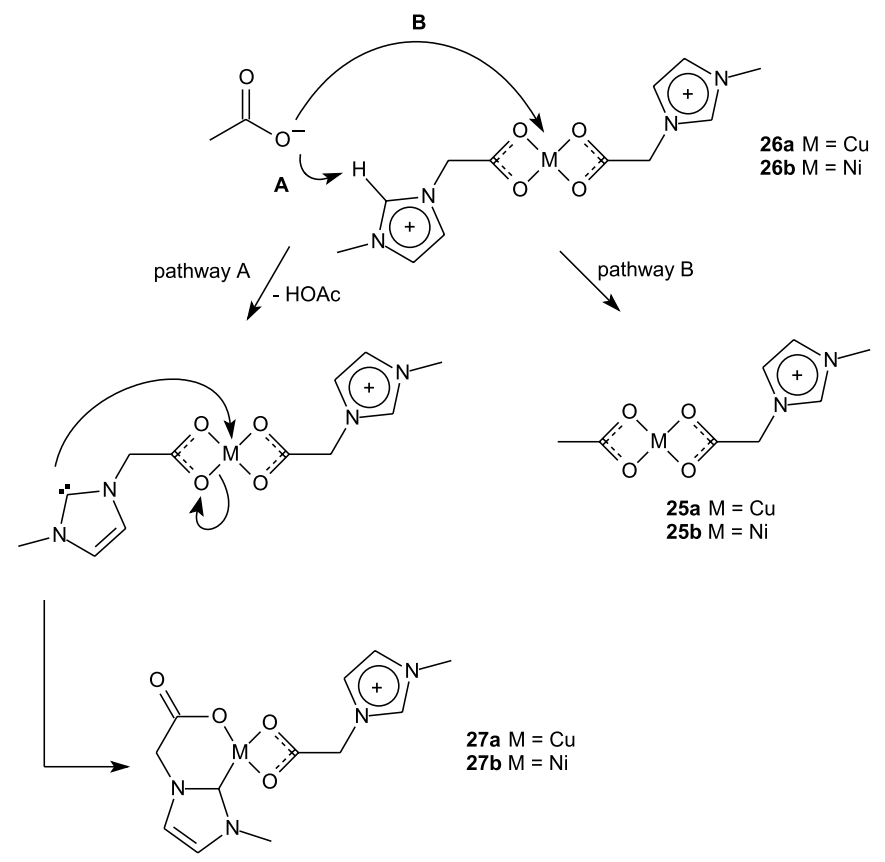

Scheme 24. Gas phase chemistry of $\mathrm{Cu}$ and Ni complexes with imidazolium ionic tags. Adapted from reference 57.

the formation of a more stable organometallic derivative through the reaction with the in situ recently formed carbene from the imidazolium moiety. The reaction with $\mathrm{Pd}(\mathrm{OAc})_{2}$, however, showed unique features in the gas phase, as shown in Scheme 25.

The presence of an acetate anion directly coordinated in the palladium center is in full accordance with the proposition of a negative palladium as an intermediate in Pd cross-coupling reactions. ${ }^{59}$ In solution, however, NMR experiments indicated the in situ formation of the organometallic palladium derivative (Scheme 26). The ionically-tagged palladium complex was synthesized (Scheme 26), characterized and successfully applied as the promoter of a phosphine-free version of the Suzuki and Heck reactions (Scheme 26) with good results.
Unfortunately, reactions conducted in ILs gave poor results for both the Heck and Suzuki reactions, probably as a consequence of the catalyst inactivation due to carbene formation in BMI.BF B $_{4}$ (or BMI.PF 6 or BMI.NTf $_{2}$ ) in the presence of different bases. Even though, the combination of a classic molecular solvent such as methanol and weak bases (e.g., $\mathrm{K}_{3} \mathrm{PO}_{4}$ or $\mathrm{K}_{2} \mathrm{CO}_{3}$ ) with the catalyst 29 proved to be a very active system for those phosphine-free reactions. For instance, in the first reaction hour, the Heck adduct was obtained in $85 \%$ and, under the same reaction conditions, the use of $\mathrm{Pd}(\mathrm{OAc})_{2}$ gave the same adduct in only $6 \%$ yield after the same time.

Very recently, we have synthesized and applied a novel ionically-tagged iron complex (Scheme 27) to promote the epoxidation of $\mathrm{C}=\mathrm{C}$ bonds for biomass derivatives. ${ }^{60}$ 

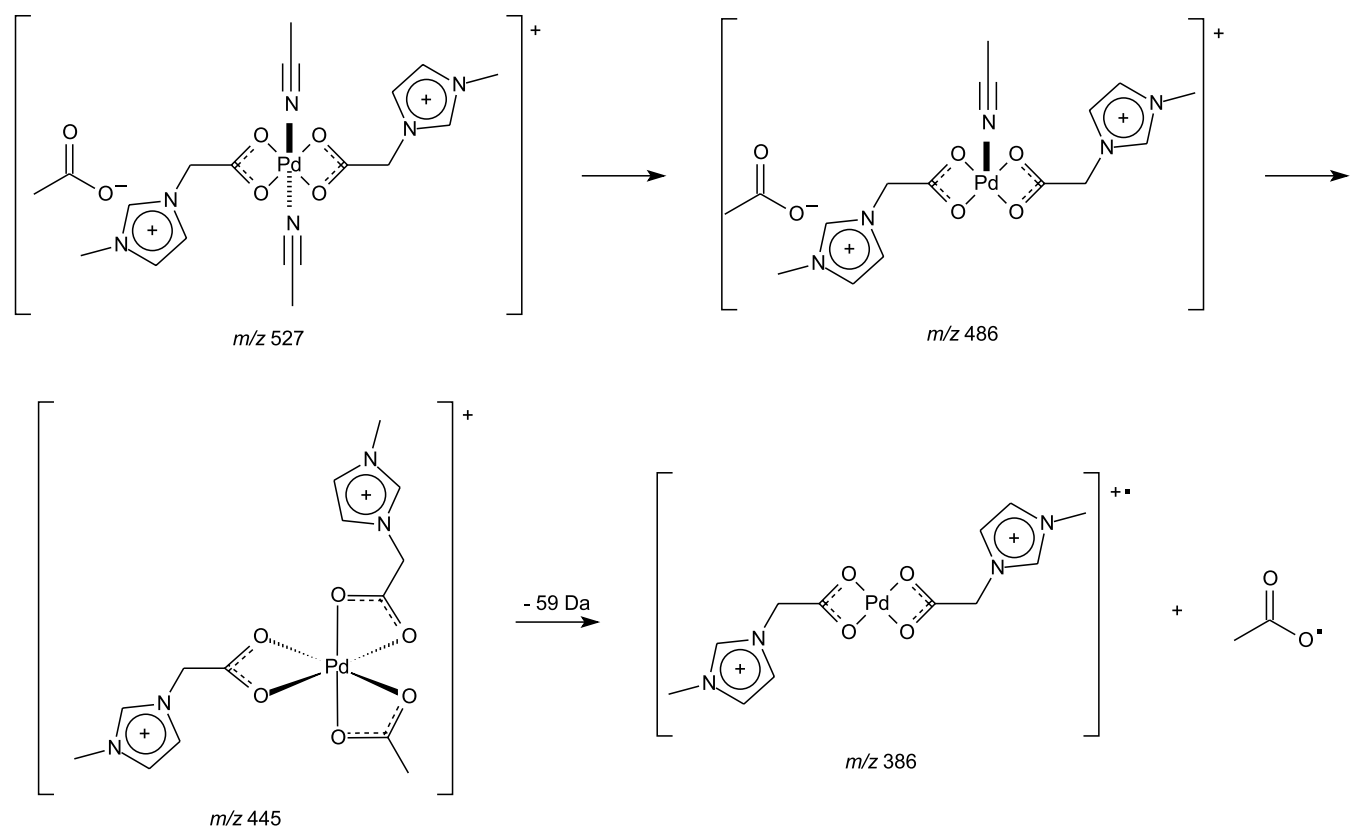

Scheme 25. Gas phase chemistry for the Pd-derivatives with imidazolium ionic tags. Note that, formally, the cation of $m / z$, 445 has a negative metal center. Adapted from reference 57.<smiles>Cn1cc[n+](CC(=O)O)c1</smiles>

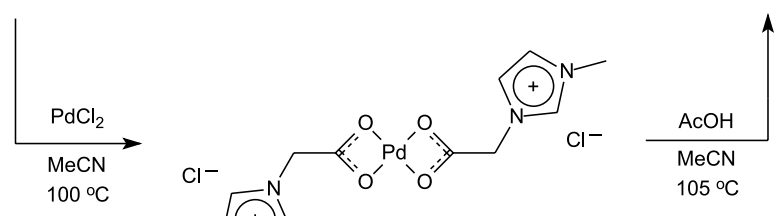

28<smiles>CN1C=CN2CC(=O)O[C@@]3(OP34(OC(=O)[O-])OC(C[n+]3ccn(C)c3)O4)C12</smiles>

Heck phosphine-free reaction

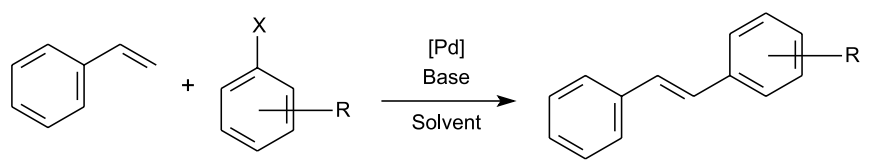

Suzuki phosphine-free reaction<smiles>[R]c1cccc(-c2ccccc2[R](=O)(O[Na])c2cccc([R])c2)c1</smiles>

Scheme 26. Synthesis of the ionically-tagged complex and the in situ formation of its organometallic derivative. Application in phosphine-free Heck and Suzuki cross-coupling reactions. 

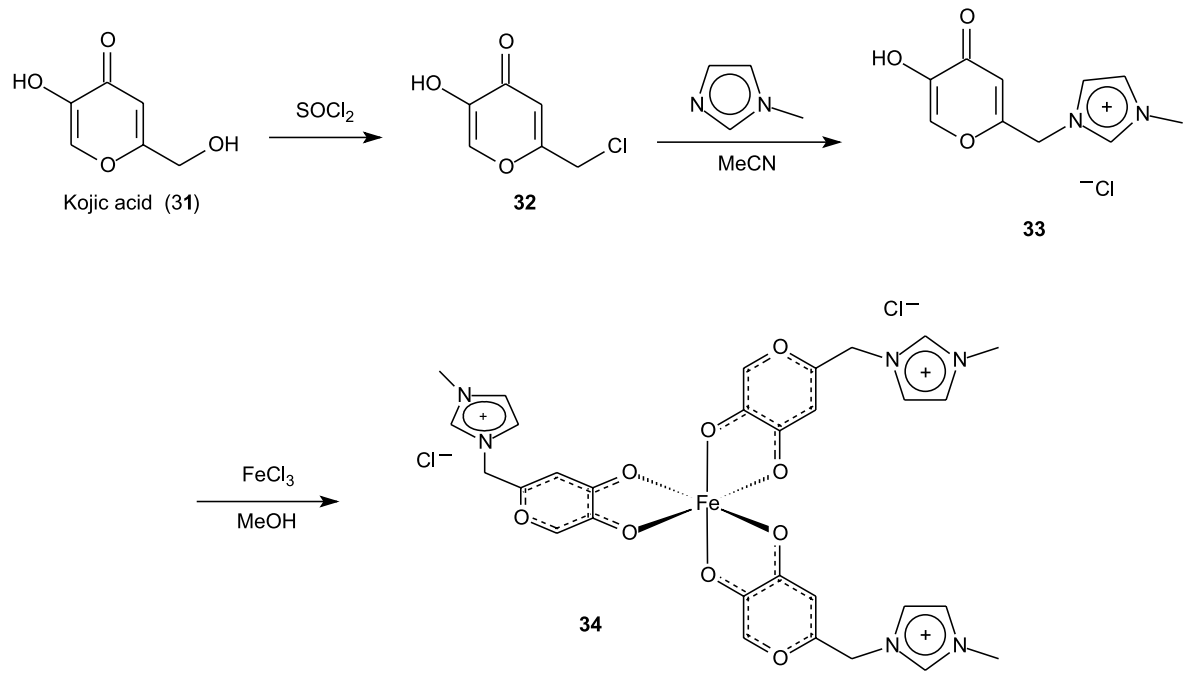

$\mathrm{Cl}^{-}$

Scheme 27. Synthesis of the new ionophilic ligand $\mathbf{3 3}$ and the ionically-tagged iron(III)-complex $\mathbf{3 4}$.

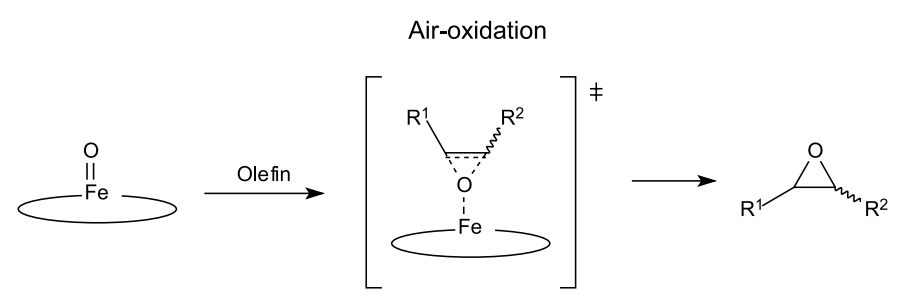

Hydroperoxide-oxidation

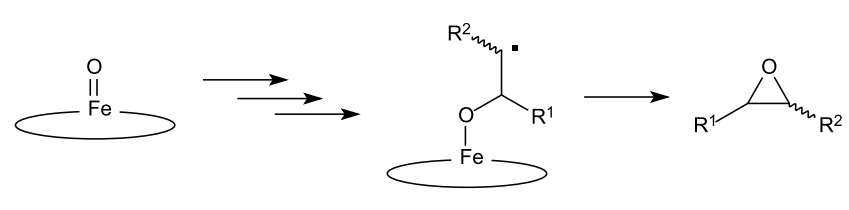

Detected intermediates and oxidizing agent

(from air oxidation reaction)

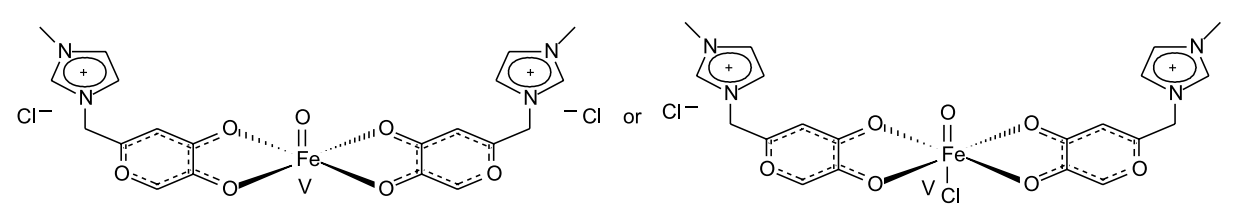

(from $\mathrm{H}_{2} \mathrm{O}_{2}$ oxidation reaction)

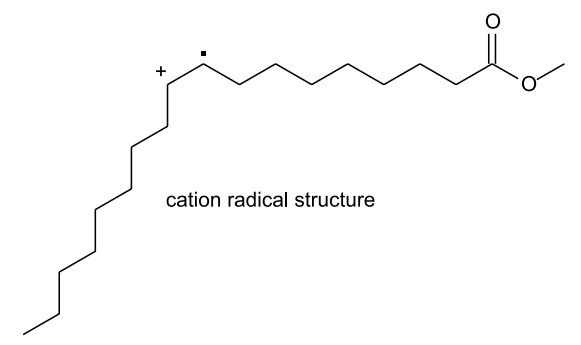

Scheme 28. Proposed mechanism and key intermediates detected by ESI-MS(/MS). 

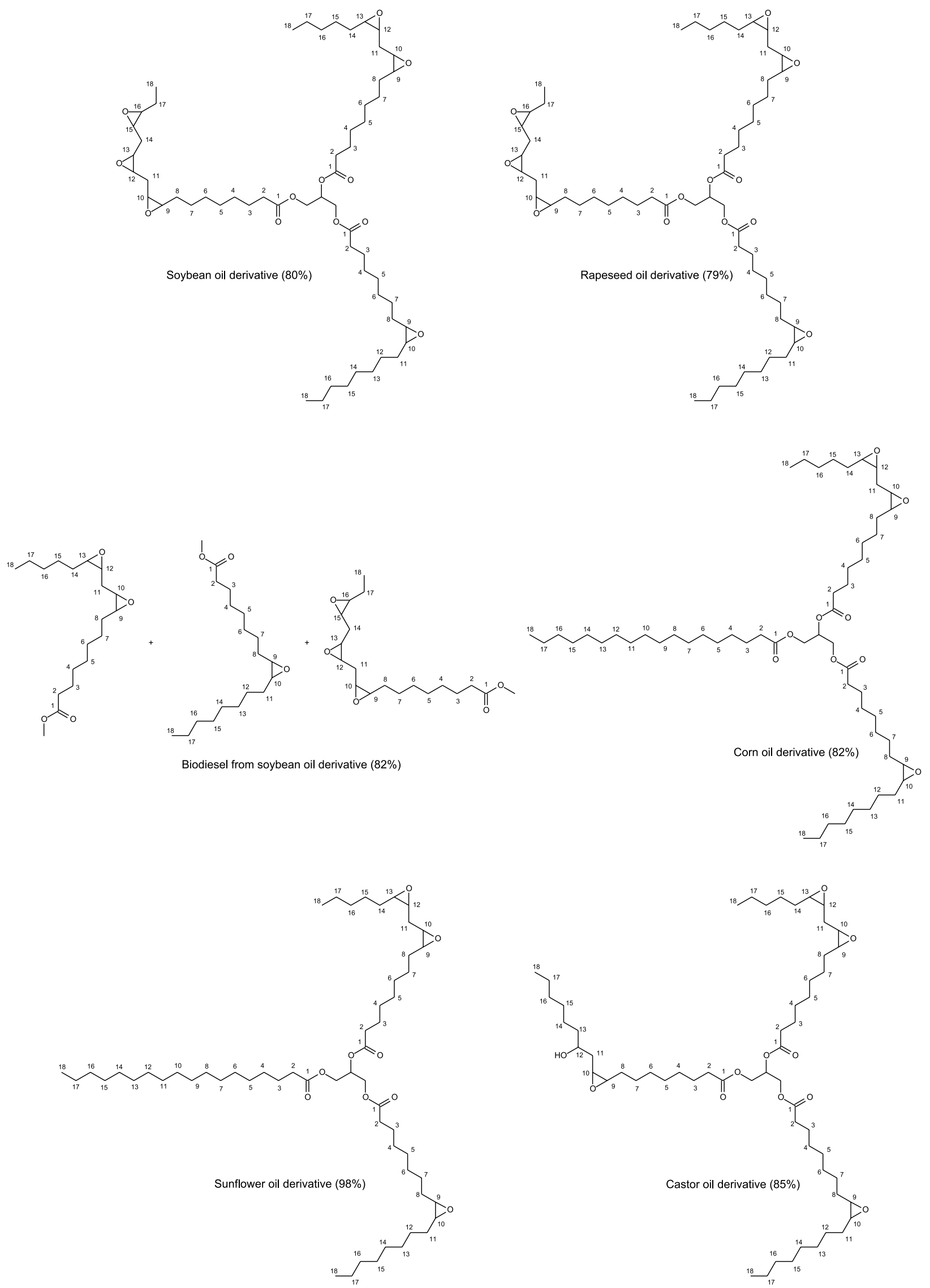

Figure 7. Epoxidation products and yields of biomass derivatives using the ionically-tagged catalyst $\mathbf{3 4}$. 
The novel catalyst $\mathbf{3 4}$ was tested in the epoxidation reaction of methyl oleate to afford EMO and DIOL (as seen in Scheme 16). The use of BMI.PF 6 and BMI.BF , as the reaction media, despite the good results (high yields), was not a good choice due to anion degradation (HF release) under the catalysis conditions, thus the best ionic media was BMI.NTf 2 . Air (oxygen) and hydrogen peroxide (30\% v/v) were tested as the oxidizing agents with success. The use of $\mathrm{H}_{2} \mathrm{O}_{2}$, nevertheless, avoided any recycle reaction due to catalyst inactivation despite the mild conditions $\left(30^{\circ} \mathrm{C}\right)$. On the other hand, the use of air as the oxidant at $90^{\circ} \mathrm{C}$, allowed the catalyst and media recovering and reutilization at least ten times without any loss in the catalyst activity. ICP-AES revealed that down to 2 ppm of iron could be found in the oil phase. The catalytic system was successfully applied with other biomass substrates and, in all cases, the epoxidized compound was obtained in high yields (Figure 7).

Another important feature of this work was the mechanistic study, which was mostly based on ESI-MS(/MS) experiments. It was noticed that reactions performed with $\mathrm{H}_{2} \mathrm{O}_{2}$ preferentially developed through a radical mechanism and, in the meantime, the air oxidation preferred a concerted mechanism (Scheme 28).

The detected and characterized intermediates have a direct influence on the comprehension of cytochrome chemistry and indicated some possibilities of action of those enzymes during the enzymatic-catalyzed oxidation processes.

\section{Summary and Outlook}

Despite all advances obtained with ILs, there are still many challenges to be overcome, drawbacks to be transposed and questions to be answered. The importance and potential of ILs achieved a level that no one could ever expect in the beginning of their development. Some important physicochemical parameters such as polarity are still under debate and others, like their distillation process, is so-far indisputable. The importance of carbenes as active catalytic species have been already reported, ${ }^{61-63}$ especially those derived of 1,3-dialkylimidazolium cation. ${ }^{63-67}$ Even though, there are many challenges surrounding the carbene chemistry and its potential applications in the field of organo- and organometallic catalysis. Without doubt, ILs are nowadays in front of a large and promising avenue towards catalysis development. Thus, the search for greener, more selective, faster and cheaper processes, necessarily points to the development of ILs their applications.

In summary, IL chemistry continues to advance with more applications in fundamental and applied processes leading to technological progress and economic impact. This has been a direct consequence of our improved understanding of the role of ILs, by the use of tags, mass spectrometry, etc. and the application of ILs to real problems in the real world where often current approaches fall short.

\section{Acknowledgements}

Coordenação de Aperfeiçoamento de Pessoal de Nível Superior (CAPES), Conselho Nacional de Desenvolvimento Científico e Tecnológico (CNPq), Financiadora de Estudos e Projetos (FINEP), Fundação de Empreendimentos Científicos e Tecnológicos (FINATEC), Fundação de Apoio à Pesquisa do Distrito Federal (FAPDF) and Decanato de Pesquisa e Pós-Graduação (DPP-UnB) are acknowledged for partial financial support. B. A. D. Neto also thanks $\mathrm{CNPq}$ for the research fellowship.

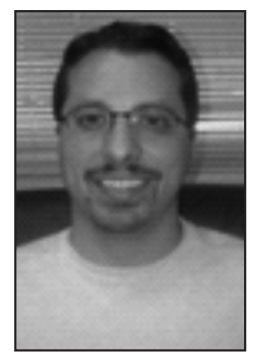

Prof. Brenno A. D. Neto received his degree in Chemistry from the Federal University of Rio Grande do Sul (UFRGS, Rio Grande do Sul State, Brazil). In 2003, he completed his MSc at the same University, and in 2006, completed his PhD under the supervision of Prof. Jaïrton Dupont and

Prof. Valentim E. U. Costa. After a period as a post-doc at the Parque Científico e Tecnológico (TECNOPUC, Rio Grande do Sul State) and as a Reader at the Pontifical Catholic University of Rio Grande do Sul (PUCRS), he became a Professor at the Chemistry Institute of the University of Brasilia (UnB). His research interests are centered on photoluminescent selective cell markers and optoelectronics, synthesis and modification of biofuels, catalysis and reactions in ionic liquids.

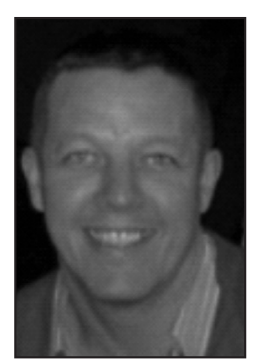

Prof. John Spencer graduated in Chemistry with French from University of Sussex (United Kingdom) in 1990. He carried out his PhD at the Université de Strasbourg (ULP, Strasbourg, France, under the supervision of Prof. Michel Pfeffer) and, after a postdoctoral stay with Prof. Antonio Togni (Swiss Federal Institute of Technology Zurich, ETH, Zurich, Switzerland), he spent ten years in the pharmaceutical sector culminating in five years at the James Black Foundation (United Kingdom). He has a long history in palladacycle chemistry, Suzuki couplings and the combination of these with microwave and parallel synthesis to make libraries of novel compounds. 


\section{References}

1. Plechkova, N. V.; Seddon, K. R.; Chem. Soc. Rev. 2008, 37, 123.

2. Zhao, H.; Malhotra, S. V.; Aldrichim. Acta 2002, 35, 75.

3. Tariq, M.; Freire, M. G.; Saramago, B.; Coutinho, J. A. P.; Lopes, J. N. C.; Rebelo, L. P. N.; Chem. Soc. Rev. 2012, 41, 829.

4. Sheldon, R. A.; Chem. Soc. Rev. 2012, 41, 1437.

5. Hallett, J. P.; Welton, T.; Chem. Rev. 2011, 111, 3508.

6. Scholten, J. D.; Leal, B. C.; Dupont, J.; ACS Catal. 2012, 2, 184.

7. Dupont, J.; de Souza, R. F.; Suarez, P. A. Z.; Chem. Rev. 2002, 102, 3667 .

8. Petkovic, M.; Seddon, K. R.; Rebelo, L. P. N.; Pereira, C. S.; Chem. Soc. Rev. 2011, 40, 1383.

9. Welton, T.; Chem. Rev. 1999, 99, 2071.

10. van Rantwijk, F.; Sheldon, R. A.; Chem. Rev. 2007, 107, 2757.

11. Martins, M. A. P.; Frizzo, C. P.; Moreira, D. N.; Zanatta, N.; Bonacorso, H. G.; Chem. Rev. 2008, 108, 2015.

12. Suarez, P. A. Z.; Consorti, C. S.; de Souza, R. F.; Dupont, J.; Goncalves, R. S.; J. Braz. Chem. Soc. 2002, 13, 106.

13. Dupont, J.; Acc. Chem. Res. 2011, 44, 1223.

14. Dupont, J.; J. Braz. Chem. Soc. 2004, 15, 341.

15. De Bellefon, C.; Pollet, E.; Grenouillet, P.; J. Mol. Catal. A: Chem. 1999, 145, 121.

16. Dubreuil, J. F.; Bazureau, J. P.; Tetrahedron Lett. 2000, 41, 7351.

17. Chauvin, Y.; Mussmann, L.; Olivier, H.; Angew. Chem., Int. Ed. 1996, 34, 2698.

18. Earle, M. J.; Esperanca, J.; Gilea, M. A.; Lopes, J. N. C.; Rebelo, L. P. N.; Magee, J. W.; Seddon, K. R.; Widegren, J. A.; Nature 2006, 439, 831.

19. Neto, B. A. D.; Santos, L. S.; Nachtigall, F. M.; Eberlin, M. N.; Dupont, J.; Angew. Chem., Int. Ed. 2006, 45, 7251.

20. Prechtl, M. H. G.; Scholten, J. D.; Neto, B. A. D.; Dupont, J.; Curr. Org. Chem. 2009, 13, 1259.

21. Amyes, T. L.; Diver, S. T.; Richard, J. P.; Rivas, F. M.; Toth, K.; J. Am. Chem. Soc. 2004, 126, 4366.

22. Mi, X. L.; Luo, S. Z.; Cheng, J. P.; J. Org. Chem. 2005, 70, 2338.

23. Kuhn, M. C. A.; Lapis, A. A. M.; Machado, G.; Roisnel, T.; Carpentier, J. F.; Neto, B. A. D.; Casagrande, O. L.; Inorg. Chim. Acta 2011, 370, 505.

24. Corilo, Y. E.; Nachtigall, F. M.; Abdelnur, P. V.; Ebeling, G.; Dupont, J.; Eberlin, M. N.; RSC Adv. 2011, 1, 73.

25. Lalli, P. M.; Rodrigues, T. S.; Arouca, A. M.; Eberlin, M. N.; Neto, B. A. D.; RSC Adv. 2012, 2, 3201.

26. Coelho, F.; Eberlin, M. N.; Angew. Chem., Int. Ed. 2011, 50, 5261.

27. Santos, L. S.; Neto, B. A. D.; Consorti, C. S.; Pavam, C. H.; Almeida, W. P.; Coelho, F.; Dupont, J.; Eberlin, M. N.; J. Phys. Org. Chem. 2006, 19, 731.
28. Lapis, A. A. M.; Neto, B. A. D.; Scholten, J. D.; Nachtigall, F. M.; Eberlin, M. N.; Dupont, J.; Tetrahedron Lett. 2006, 47, 6775 .

29. Johnson, K. E.; Pagni, R. M.; Bartmess, J.; Monatsh. Chem. 2007, 138, 1077 .

30. Wong, W. L.; Wong, K. Y.; Can. J. Chem. 2012, 90, 1.

31. Sawant, A. D.; Raut, D. G.; Darvatkar, N. B.; Salunkhe, M. M.; Green Chem. Lett. Rev. 2011, 4, 41.

32. Zhang, Q. H.; Zhang, S. G.; Deng, Y. Q.; Green Chem. 2011, 13, 2619 .

33. Neto, B. A. D.; Ebeling, G.; Goncalves, R. S.; Gozzo, F. C.; Eberlin, M. N.; Dupont, J.; Synthesis 2004, 1155.

34. Pilli, R. A.; Robello, L. G.; Camilo, N. S.; Dupont, J.; Lapis, A. A. M.; Neto, B. A. D.; Tetrahedron Lett. 2006, 47, 1669.

35. Neto, B. A. D.; Alves, M. B.; Lapis, A. A. M.; Nachtigall, F. M.; Eberlin, M. N.; Dupont, J.; Suarez, P. A. Z.; J. Catal. 2007, 249, 154.

36. Lapis, A. A. M.; de Oliveira, L. F.; Neto, B. A. D.; Dupont, J.; ChemSusChem 2008, 1, 759.

37. Liu, C. Z.; Wang, F.; Stiles, A. R.; Guo, C.; Appl. Energy 2012 , 92, 406.

38. Earle, M. J.; Plechkova, N. V.; Seddon, K. R.; Pure Appl. Chem. 2009, 81, 2045.

39. Cordeiro, C. S.; da Silva, F. R.; Wypych, F.; Ramos, L. P.; Quim. Nova 2011, 34, 477.

40. Narayan, M. P.; Kumar, S. S.; Arunrao, A. S.; Karthikeyan, P.; Rambhau, B. P.; Res. J. Chem. Environ. 2011, 15, 92.

41. Silva, W. S. D.; Lapis, A. A. M.; Suarez, P. A. Z.; Neto, B. A. D.; J. Mol. Catal. B: Enzym. 2011, 68, 98.

42. Hagiwara, H.; Heterocycles 2012, 85, 281.

43. Chaturvedi, D.; Curr. Org. Chem. 2011, 15, 1236.

44. Dupont, J.; Scholten, J. D.; Chem. Soc. Rev. 2010, 39, 1780.

45. Zahmakiran, M.; Ozkar, S.; Nanoscale 2011, 3, 3462.

46. Carvalho, M. S.; Lacerda, R. A.; Leao, J. P. B.; Scholten, J. D.; Neto, B. A. D.; Suarez, P. A. Z.; Catal. Sci. Technol. 2011, 1, 480.

47. da Silva, J. F. M.; Garden, S. J.; Pinto, A. C.; J. Braz. Chem. Soc. 2001, 12, 273.

48. Pinto, A. C.; Lapis, A. A. M.; da Silva, B. V.; Bastos, R. S.; Dupont, J.; Neto, B. A. D.; Tetrahedron Lett. 2008, 49, 5639.

49. Chiappe, C.; Rajamani, S.; Eur. J. Org. Chem. 2011, 5517.

50. Allen, C. L.; Williams, J. M. J.; Chem. Soc. Rev. 2011, 40, 3405.

51. de Oliveira, V. M.; de Jesus, R. S.; Gomes, A. F.; Gozzo, F. C.; Umpierre, A. P.; Suarez, P. A. Z.; Rubim, J. C.; Neto, B. A. D.; ChemCatChem 2011, 3, 1911.

52. Lee, S. G.; Chem. Commun. 2006, 1049.

53. Lombardo, M.; Trombini, C.; ChemCatChem 2010, 2, 135.

54. Sebesta, R.; Kmentova, I.; Toma, S.; Green Chem. 2008, 10, 484.

55. Shaughnessy, K. H.; Chem. Rev. 2009, 109, 643.

56. Dupont, J.; Spencer, J.; Angew. Chem., Int. Ed. 2004, 43, 5296. 
57. Oliveira, F. F. D.; dos Santos, M. R.; Lalli, P. M.; Schmidt, E. M.; Bakuzis, P.; Lapis, A. A. M.; Monteiro, A. L.; Eberlin, M. N.; Neto, B. A. D.; J. Org. Chem. 2011, 76, 10140.

58. Li, J. Z.; Peng, Y. Q.; Song, G. H.; Catal. Lett. 2005, 102, 159.

59. Amatore, C.; Jutand, A.; Acc. Chem. Res. 2000, 33, 314.

60. dos Santos, M. R.; Diniz, J. R.; Arouca, A. M.; Gomes, A. F.; Gozzo, F. C.; Tamborim, S. M.; Parize, A. L.; Suarez, P. A. Z.; Neto, B. A. D.; ChemSusChem 2012, 5, 716.

61. Bugaut, X.; Glorius, F.; Chem. Soc. Rev. 2012, 41, 3511.

62. Fortman, G. C.; Nolan, S. P.; Chem. Soc. Rev. 2011, 40, 5151.

63. Phan, N. T. S.; Van Der Sluys, M.; Jones, C. W.; Adv. Synth. Catal. 2006, 348, 609.
64. Monge-Marcet, A.; Pleixats, R.; Cattoen, X.; Man, M. W. C.; Catal. Sci. Technol. 2011, 1, 1544.

65. Liu, S. F.; Xiao, J. L.; J. Mol. Catal. A: Chem. 2007, $270,1$.

66. Giernoth, R. In In Situ Nmr Methods in Catalysis, vol. 276; Bargon, J.; Kuhn, L. T., eds.; Springer-Verlag: Heidelberg, Germany, 2007, p. 1.

67. Lin, I. J. B.; Vasam, C. S.; J. Organomet. Chem. 2005, 690, 3498.

Submitted: April 24, 2012

Published online: May 22, 2012 